Revista Brasileira de Meteorologia, v.26, n.3, 349 - 366, 2011

\title{
ESTIMATIVA DOS RECURSOS EÓLICOS NO LITORAL CEARENSE USANDO A TEORIA DA REGRESSÃO LINEAR
}

\author{
MARCOS ANTONIO TAVARES LIRA ${ }^{1}$, EMERSON MARIANO DA SILVA ${ }^{2}$, JOSÉ MARIA BRABO \\ ALVES $^{3}$
}
${ }^{1}$ Universidade Federal do Piauí, Departamento de Engenharia Elétrica (UFPI/DEE), Teresina, PI, Brasil ${ }^{2}$ Universidade Estadual do Ceará (UECE), Fortaleza, CE, Brasil
${ }^{3}$ Fundação Cearense de Meteorologia e Recursos Hídricos (FUNCEME), CE, Brasil

marcoslira@ufpi.edu.br, emerson@uece.br, brabo@funceme.br

Recebido Agosto 2010 - Aceito Fevereiro 2011

\begin{abstract}
RESUMO
O trabalho apresentado trata da estimativa de recursos eólicos no litoral cearense, usando a teoria da regressão linear. Seu objetivo principal é estimar valores de velocidade média do vento em altitude a partir de dados observados a 10 metros. Duas regiões são investigadas: Paracuru e Camocim, ambas situadas no Estado do Ceará. Para cada região será adotado o mesmo procedimento. Inicialmente, caracteriza-se a região a partir do perfil diário e mensal de velocidade média do vento obtidos dos dados brutos da respectiva Plataforma de Coleta de Dados (PCD) e Torre Anemométrica (TA) da região. Os dados caracterizadores da direção predominante do vento também são utilizados. Utilizando-se a equação do perfil logarítmico do vento estimam-se os valores de velocidade média do vento às altitude de 20, 40 e 60 metros, a partir dos dados observados em superfície a 10 metros, calculando-se em seguida os coeficientes de correlação entre esses dados estimados em altitude e os observados na TA da região. Utiliza-se, em seguida, o modelo de regressão linear para se estimar novos valores em altitude. Inicialmente esse procedimento é feito para um período de calibração do modelo e em seguida para o período de validação do mesmo. Em ambos os períodos o modelo de regressão linear mostrou um bom desempenho, quer seja pelo alto índice de concordância entre as séries de dados estimados e observados e seus respectivos coeficientes de correlação, quer seja pelos baixos valores dos erros entre essas séries. Palavras - chave: Energia eólica, Litoral cearense, Regressão linear, Estimativa de ventos.
\end{abstract}

\begin{abstract}
ABSTRATC: ESTIMATE OF WIND RESOURCES IN THE COAST OF CEARÁ USING THE LINEAR REGRESSION THEORY.

The current study deals with the estimation of wind resources in the coast of Ceará using the linear regression theory. Its main objective is to estimate average wind speed values at different altitudes from observed data at surface. Two areas located in the State of Ceará are investigated: Paracuru and Camocim. For each region the same procedure will be adopted. Initially the region is characterized by the daily and monthly mean wind speed profile obtained from the local Platform for Data Collection (PCD) and anemometric tower (TA) raw data. The prevailing wind direction data are also used. The logarithmic wind profile equation is used to estimate the values of average wind speed at altitudes of 20, 40 and 60 meters from the observed data at $10 \mathrm{~m}$ surface, then calculating the correlation coefficients between the estimated altitude data and the observed TA data in the region. Then, the linear regression model is used to estimate new values in altitude. Initially this procedure is done for a period of model calibration and then for a period of validation. In both periods the linear regression model showed a good performance either by the high correlation coefficient values between the estimated and observed data series, or the low values of the errors between the series.
\end{abstract}

Keywords: Wind power, Coastal Ceará, Linear regression, Estimate winds. 


\section{INTRODUÇÃO}

Assegurar o acesso a fontes de energia limpas e sustentáveis é, sem dúvida, um dos grandes desafios enfrentados pelo mundo moderno (Dobriansky, 2006). Diariamente, os meios midiáticos abordam direta ou indiretamente algum assunto que está relacionado com a energia.

O incentivo e a promoção do uso da energia, a partir de recursos eólicos, devem ser diretrizes permanentemente presentes nas políticas públicas voltadas para a segurança energética nacional. : O Ceará alcançou em 2010, a marca de 518,33 MW de potência instalada em geração de energia eólica e se tornou o principal produtor desse tipo de energia no Brasil. Desse total, 500,93 MW são oriundos dos 14 parques eólicos que estão sendo implantados desde 2007 e 17,4 MW, de três parques instalados na década de 1990.

Relacionado à questão energética, é importante citar o conceito de complementaridade hidro-ambiental do sistema de produção de energia associado à variabilidade das fontes energéticas. Este conceito tem como base o ciclo climático sazonal da precipitação (fonte responsável maior produção de energia hidroelétrica no Brasil) e as outras variáveis atmosféricas como velocidade do vento e radiação solar. Por exemplo, no Nordeste Brasileiro, o primeiro semestre é marcado sazonalmente, não levando em consideração a variabilidade interanual, como um período marcado por chuvas, maior índice de nebulosidade e menores velocidades do vento, sendo o período mais favorável a geração de energia hidráulica. Quando diminuem ou cessam as chuvas a partir do mês de junho no semiárido, há um período preferencial ao uso do potencial eólico devido o aumento da velocidade dos ventos e um aumento da radiação solar devido à diminuição da nebulosidade (Oliveira, 2007; Santiago de Maria et al., 2006).

A variabilidade destes parâmetros meteorológicos é condicionada pela influência de sistemas meteorológicos predominantes e suas atuações durante o ano na região, e as peculiaridades locais da camada limite, que proporcionam em particular à circulação dos ventos algumas características diferenciadas.

No Nordeste do Brasil a atuação de sistemas meteorológicos marca o ciclo climático sazonal do vento na região. Em média, entre os meses de novembro a janeiro, a incursão freqüente de sistemas frontais, que se deslocam dos sub-trópicos da América do Sul para o setor centro-sul do Nordeste causando chuvas nessa região, tendem a manter ventos soprando com predomino de sudoeste para nordeste e em alguns casos de sul para o norte (Kousky, 1979).

No verão e outono austrais (janeiro a maio), os ventos passam a soprar climatologicamente entre os quadrantes norte e leste, prevalecendo ventos de nordeste. Em alguns anos há influências diferentes neste setor associado a variabilidade interanual das anomalias de temperatura do mar no Atlântico tropical (Andreoli et al. 2004), que podem alterar este regime. Anos em que as anomalias de TSM do Atlântico Tropical Norte estão mais quentes que as anomalias de TSM no Atlântico Tropical Sul, há uma freqüência maior de ventos soprando de sudeste nesta região do NEB (Xavier et al. 2000). Porém, neste período de janeiro a maio, em particular março e abril, sobre o setor norte do Nordeste do Brasil a Zona de Convergência Intertropical (ZCIT) atua causando eventos de chuvas mais freqüentes na região, e em geral, a ocorrência de ventos mais fracos sobre esta área do Nordeste.

A partir de junho até início de novembro o Nordeste semi-árido é marcado por um período de reduzida precipitação, exceto o setor leste da Região que tem seu período chuvoso centrado entre abril e julho, com influência dos chamados distúrbios ondulatórios de leste, perturbações atmosféricas que se deslocam do oceano Atlântico na direção do continente provocando chuvas na chamada zona da mata nordestina (Rao et al., 1993). Como não só em grande parte do Nordeste do Brasil, mas como em grande parte da América do Sul, entre junho e novembro predomina uma massa de ar seco, a ela associa-se o deslocamento do sistema de alta pressão denominado de Anti-Ciclone semi-estacionário para a costa leste-sudeste do Brasil, ocasionando sobre o Nordeste o predomínio de ventos soprando entre os quadrantes leste-sudeste. Este sistema no primeiro semestre do ano tem sua localização preferencial no setor sudeste do Oceano Atlântico.

Além destas características sinóticas que influenciam o regime de ventos no Nordeste do Brasil interanualmente, área objeto do estudo, circulações locais como as brisas terrestres e marítimas e os efeitos locais da camada limite planetária, associados principalmente aos seus processos turbulentos, são também fatores que tem papel importante nas mudanças de direção e velocidade dos ventos na escala diária (Hirata et al. 1986; Stull, 1988; Roballo e Fisch, 2008; Alcântara e Souza, 2008; Teixeira, 2008). As brisas terrestres e marítimas ocasionadas pelo contraste térmico continente oceano são responsáveis pelas trocas na direção dos ventos durante o dia e noite nas áreas costeiras do Nordeste. Durante o dia, principalmente à tarde, quando o continente é mais quente que o mar, gera um centro de pressões mais baixas e o vento tende soprar para o interior do continente, caracterizando a brisa marítima. Durante a noite, as características são contrárias, o mar perde calor mais lentamente que o continente, gerando pressões mais baixas e ocasionando um fluxo de ventos que sopram do continente na direção dos oceanos, definindo a brisa terrestre. Processos de instabilidade atmosférica na camada limite, características como a rugosidade do terreno, diferenças de vegetação e a própria configuração topográfica são também responsáveis 
por trocas diurnas no regime, na velocidade e direção do vento (Alcântara e Sousa, 2008; Roballo e Fisch, 2008).

Quando se pretende verificar se uma determinada região é um potencial sítio eólico, faz-se necessário que se tenham dados confiáveis de direção e velocidade média do vento. Constata-se, através de estudos citados neste trabalho, que a maioria dos dados anemométricos é obtida em superfície (10 metros de altura), quando o ideal seria a obtenção desses dados na altura onde se pretende instalar o gerador eólico. Na prática, tentando-se amenizar o problema, pode-se recorrer à instalação de torres anemométricas que, durante um curto intervalo de tempo ( $2 \mathrm{ou}$ 3 anos), irão coletar esses dados. No entanto, o dispêndio de recursos técnicos e financeiros para se instalar uma TAé elevado. E foi nessa perspectiva que este trabalho foi desenvolvido, uma vez que o mesmo apresenta um método para que a partir dos dados de superfície seja possível estimar valores de velocidade do vento em altitudes nas quais os geradores eólicos são instalados.

\section{METODOLOGIA E DADOS}

No desenvolvimento deste trabalho duas regiões geográficas distintas do Estado do Ceará são investigadas. A primeira se refere à região de Paracuru e a segunda à região de Camocim. Para fins de localização geográfica, as Figuras 1 e 2 apresentam o mapa do Estado do Ceará com destaque para a região de estudo e sua respectiva TA e $\mathrm{PCD}$.

A região de Paracuru compreende a TA situada na cidade de Paracuru e a PCD situada na cidade de São Gonçalo do Amarante (SGA). A TA situada na cidade de Paracuru está instalada num ponto com as coordenadas geográficas: $03^{\circ} 24^{\prime} 42,4^{\prime \prime}$ S e $38^{\circ} 59^{\prime} 02,8^{\prime \prime} \mathrm{W}$. Já a PCD, situada na cidade de SGA está instalada num ponto de coordenadas $03^{\circ} 39^{\prime} 0,8^{\prime \prime} \mathrm{S}$ e $38^{\circ} 56^{\prime} 32,6^{\prime \prime} \mathrm{W}$. O anemógrafo utilizado para medição na TA possui uma taxa de amostragem de $0,5 \mathrm{~Hz}$ (sinais instantâneos a cada 2 segundos), e realiza registros em intervalos de integração de 10 minutos.

A região de Camocim compreende a TA situada na cidade de Camocim e a PCD situada na cidade de Barroquinha (BAR). A TA, situada na cidade de Camocim, está instalada no ponto com as coordenadas geográficas: $02^{\circ} 51^{\prime} 56,7^{\prime \prime} \mathrm{S}$ e 4053'09,2”W. Já a PCD, situada na cidade de BAR, está instalada no ponto de coordenadas $2^{\circ} 55^{\prime} 48,2^{\prime \prime} \mathrm{S}$ e $41^{\circ} 7^{\prime} 7,3^{\prime \prime} \mathrm{W}$.

Os dados de velocidade e direção dos ventos utilizados neste estudo foram obtidos a partir de duas fontes: das Plataformas de Coleta de Dados (PCDs), monitoradas pela FUNCEME, e das Torres Anemométricas (TAs) de propriedade da SEINFRA/CE. As TAs são dotadas de sensores para medição da velocidade do vento em três níveis (20, 40 e 60 metros) e da direção do vento em dois níveis (40 e 60 metros). Já as PCDs possuem sensores para medição da velocidade e direção do vento à 10 metros da

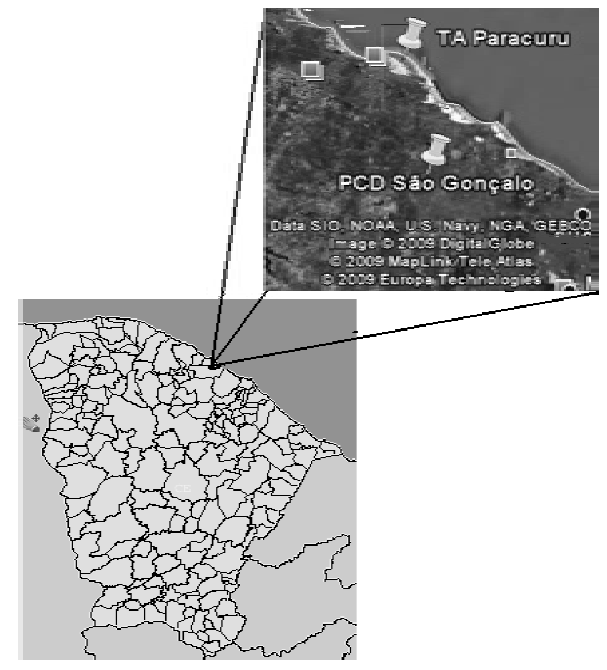

Figura 1 - Mapa do estado do Ceará destacando-se a região de estudo (Paracuru).

Fonte: Adaptada do Google mapas.

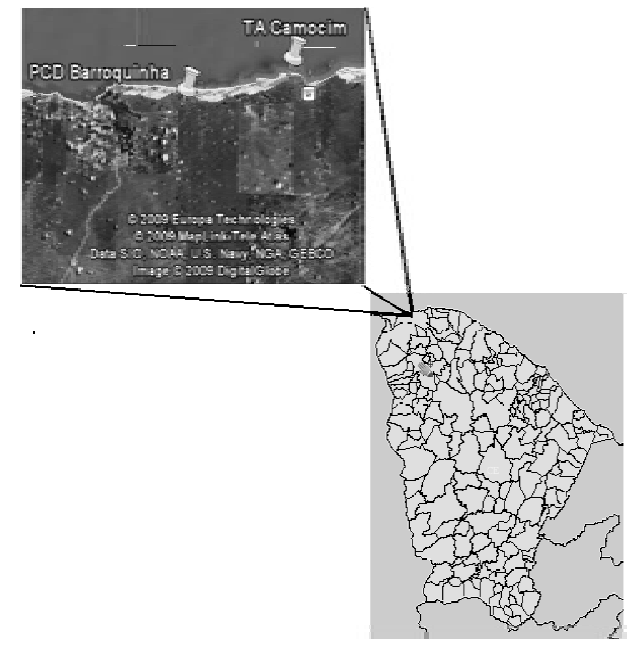

Figura 2 - Mapa do estado do Ceará destacando-se a região de estudo (Camocim).

Fonte: Adaptada do Google mapas.

superfície. Os dados de velocidade de vento, tanto das TAs, quanto das PCDs, foram utilizados para o levantamento das médias diárias, de 5, 10 e de 15 dias, em ambas as regiões de estudo.

Com os dados disponíveis de velocidade e direção do vento desenvolveu-se a primeira etapa proposta na metodologia deste trabalho. Vale ressaltar que foram identificados, nos dados brutos, alguns valores inconsistentes e até mesmo inexistentes. Para solucionar esse problema optou-se pela utilização do método de preenchimento de falhas denominado método de validação cruzada.

O método de validação cruzada é o procedimento mediante o qual cada amostra é retirada do conjunto de dados, e é feita uma interpolação para avaliar seu valor. A validação cruzada assume que em um determinado ponto, que não 
tenha sido coletado os dados, o valor é estimado a partir dos dados circundantes. Após essa estimativa, o valor poderá ser re-introduzido na série de dados.

Considerando-se o objetivo deste trabalho, fez-se necessário correlacionar os dados das PCDs com os dados das TAs a fim de se investigar o quanto um conjunto de dados explica a variabilidade do outro. Assim, na região de Paracuru correlacionou-se os dados da TA da cidade de Paracuru com os dados da PCD de SGA, enquanto que na região de Camocim correlacionou-se os dados da TA da cidade de Camocim com os dados da PCD da BAR.

Os dados relacionados à TA de Paracuru e à PCD de SGA foram extraídos de uma série temporal que vai de 18/08/04 a 09/05/06, totalizando 630 dias de observações. Essa série foi dividida em duas partes, sendo que o período que compreende os primeiros 360 dias foi chamado de período de calibração, e o período que compreende os 270 dias restantes foi chamado de período de validação do modelo. Já os dados relacionados à TA de Camocim e à PCD de BAR foram extraídos de uma série temporal que vai de 22/08/04 a 12/02/06, totalizando 540 dias de observações. Essa série também foi dividida em duas partes, sendo que o período de calibração compreende os primeiros 360 dias, e o período de validação compreende os 180 dias restantes. A razão pela qual se utilizou uma serie temporal menor para esta região baseia-se no fato de que o período de dados observados é limitado.

Tanto para a região de Camocim quanto para a região de Paracuru, a partir das séries de dados de velocidade do vento nas PCDs e nas TAs, calcularam-se as médias em quatro intervalos distintos (diários, 5,10 e 15 dias). Em seguida, adotando-se os dados da PCD como referência, aplicou-se os mesmos na equação do perfil logarítmico do vento dada por:

$$
v(\mathrm{z})=v\left(\mathrm{Z}_{\mathrm{R}}\right) \frac{\ln \left(\frac{\mathrm{z}}{\mathrm{Z}_{0}}\right)}{\ln \left(\frac{\mathrm{Z}_{\mathrm{R}}}{\mathrm{Z}_{\mathrm{0}}}\right)}
$$

em que $v\left(Z_{R}\right)$ é a velocidade média à altura de referência $Z_{R}$.

A Equação 1 foi utilizada a fim de se estimar valores da velocidade do vento à 20 metros, à 40 metros e à 60 metros de altura e a partir daí se estabelecer uma comparação com os dados da respectiva TA. Vale ressaltar, que na aplicação da equação acima citada, foi adotado o valor de $\mathrm{Z}_{0}$ da literatura para regiões litorâneas, que é de 0,0002 (Carvalho, 2003; Castro, 2007).

Na sequência, para o período de calibração, investigou-se a existência de correlação para os três níveis de altura entre os dados estimados a partir dos dados em superfície, coletados nas PCDs, e os dados observados em altitude nas TAs. Cada diagrama de dispersão construído no período de calibração gerou a equação de uma reta, bem como, seu respectivo coeficiente de determinação. A partir de então, aplicou-se o modelo de regressão linear, ajustando-se os dados de tal maneira que cada par ordenado (valor observado TA, valor estimado PCD) estivesse exatamente sobre suas respectivas retas. Assim, para cada equação da forma $y$ $=\beta_{0}+\beta_{1} x$, aplicando-se os valores de $\mathbf{y}$ (valores obtidos das PCDs pela aplicação da Equação 1), obteve-se novos valores de $x$ ou $x$ '.

Em seguida verificou-se a relação de $x$ (valores de velocidades do vento observados nas TAs) com $x$ '(valores de velocidades do vento estimados nas TAs). Nessa verificação foram quantificados, além dos coeficientes de correlação e determinação, os erros através das medidas do Erro Médio Quadrático (Root Mean Squared Error - RMSE), do Erro Absoluto Médio (Mean Absolute Error - MAE) e do erro percentual ( $\varepsilon$ ) entre os valores estimados e os observados. As medidas RMSE, MAE e $\varepsilon$, são expressas, respectivamente, por:

$$
\begin{aligned}
& \text { RMSE }=\sqrt{\frac{\sum_{i=1}^{n}\left(p_{i}-o_{i}\right)^{2}}{n}} \\
& M A E=\frac{\sum_{i=1}^{n}\left|p_{i}-o_{i}\right|}{n} \\
& \varepsilon=100 \% \cdot \frac{\left(p_{i}-o_{i}\right)}{o_{i}}
\end{aligned}
$$

em que, $p_{i}$ representa o valor estimado; $o_{i}$ representa o valor observado e $n$ indica o número de observações.

Segundo Zacharias et al. (1996) (apud Carvalheiro, 2008), o RMSE mede a variação dos valores estimados ao redor dos valores medidos. Enquanto que o MAE indica o afastamento (desvio) médio absoluto dos valores previstos em relação aos valores observados. Já o $\varepsilon$ representa o afastamento percentual entre $\mathrm{o}$ valor real medido e $\mathrm{o}$ inferido. $\mathrm{O}$ ideal seria que os valores de MAE, de RMSE e de $\varepsilon$ fossem o mais próximo de zero.

Para o período de validação aplicou-se a regressão linear, seguindo-se o mesmo procedimento adotado para o período de calibração, ou seja, aplicando-se os valores de $\mathbf{y}$ (valores obtidos das PCDs pela aplicação da Equação 1) e obtendo-se $x$ '. Novamente verificou-se a relação de $\boldsymbol{x}$ (valores de velocidades do vento observados nas TAs) $\operatorname{com} \boldsymbol{x}$ ' (valores de velocidades do vento estimados nas TAs). Nessa verificação foram calculados os novos erros e os novos valores dos coeficientes de correlação.

\section{RESULTADOS E DISCUSSÕES}

\subsection{Resultados para a região de Paracuru}

\subsubsection{Caracterização do regime de ventos na região de Paracuru}

As Figuras 3 e 4 mostram respectivamente o perfil diário e mensal da velocidade média do vento, a partir de dados coletados na PCD de SGA. 
Em relação ao perfil de velocidade média diária do vento na região de SGA, observa-se que durante o período diurno, compreendido entre 06:00 e 18:00 horário local, tem-se os maiores valores de velocidade média do vento, com ocorrência de valor máximo de $6,3 \mathrm{~m} / \mathrm{s}$, aproximadamente às $15: 00 \mathrm{~h}$ horário local. Essa maior intensidade nas velocidades médias do vento no período diurno explica-se pela presença de brisas marítimas, conforme exposto por Barreto et al. (2002) e por Molion e Bernardo (2000).

Para o perfil de velocidade média mensal do vento, tem-se que os maiores valores de velocidade média ocorrem no período de julho a dezembro, coincidindo com a estação seca da região. Adicionalmente, têm-se os menores valores de velocidade média do vento no período de janeiro a maio, período de estação chuvosa da região, confirmando os resultados de Sacramento et al. (2006).

Considerando-se que os mais recentes geradores eólicos instalados no Estado do Ceará, modelo E 701.8 da fabricante Wobben (fonte: Wobben Windpower), possuem em sua curva de potência, uma velocidade de entrada - velocidade na qual se tem o início da geração - de $2,5 \mathrm{~m} / \mathrm{s}$, evidencia-se que os valores de velocidade média do vento mostrados nos perfis diários e mensais são significativamente favoráveis à produção de energia eólica, uma vez que os mesmos estão, em sua maioria, acima desse valor de entrada.

As Figuras 5 e 6 mostram, respectivamente, o perfil diário e mensal de velocidade média do vento na TA de Paracuru a partir dos dados coletados em altitude. Os resultados mostram que, em altitude, têm-se maiores velocidades médias do vento, se comparadas com os dados da PCD de SGA.

Para o perfil diário de velocidade média do vento, observa-se o ciclo diurno bem estabelecido, assim como na PCD de SGA, com ocorrência de valor máximo de velocidade média do vento por volta das $15 \mathrm{~h}$ horário local.

Para o perfil mensal, os períodos onde se tem os maiores e os menores valores de velocidades médias do vento são

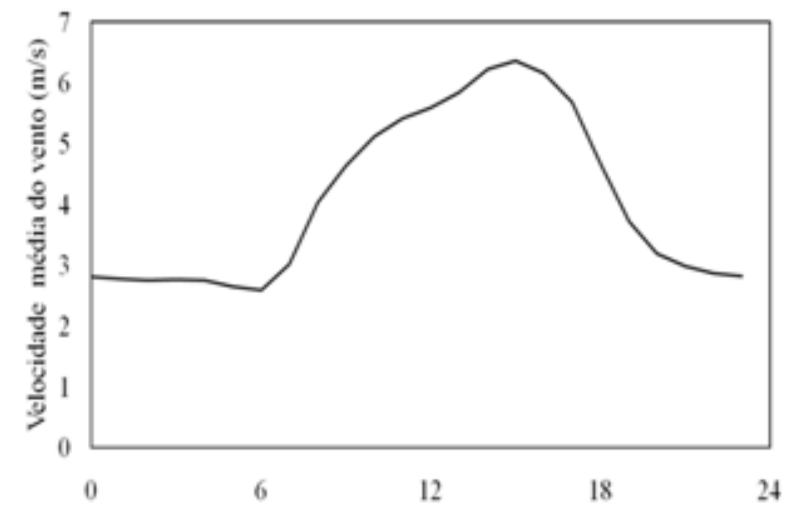

Figura 3 - Perfil diário da velocidade do vento na PCD de São Gonçalo do Amarante. semelhantes aos citados para a PCD de SGA, caracterizando, desta forma, a região de Paracuru como um potencial sítio para geração eólica no Estado do Ceará.

As figuras mostram ainda que, em altitude, se tem valores de velocidade média diária do vento que chegam a aproximadamente $10,0 \mathrm{~m} / \mathrm{s}$ e que os valores médios mensais de velocidade, mesmo no período chuvoso, ultrapassam os $4,0 \mathrm{~m} / \mathrm{s}$, valor que está acima da velocidade de entrada do aerogerador.

Nas Figuras 7 e 8 apresentam-se a direção predominante do vento na região da $\mathrm{PCD}$ de SGA e na região da TA de Paracuru, respectivamente.

Observa-se na Figura 7 que a direção predominante do vento na região de SGA é de leste, tendo-se ao longo do ano variações entre as direções sudoeste e nordeste. Na Figura 8, observa-se que a direção predominante do vento em Paracuru é de leste, com variações entre as direções de sudeste e nordeste ao longo do ano. Assim, tem-se de forma evidente, a influência dos Ventos Alísios na região, como mencionado em Barreto et al. (2002).

\subsubsection{Período de calibração - região de Paracuru}

As Figuras 9, 10 e 11 apresentam as correlações entre os valores da velocidade média do vento estimados para $60,40 \mathrm{e}$ 20 metros, respectivamente, através dos dados observados em superfície na PCD de SGA, e os valores observados na TA de Paracuru.

Em adição, nessas figuras têm-se as equações das retas correspondentes aos ajustes de regressão linear juntamente com os coeficientes de determinação $\left(\mathrm{R}^{2}\right)$ obtidos para médias diárias, de 5 , de 10 e de 15 dias.

As figuras mostram ainda que, na medida em que se aumenta o período de cálculo das médias de velocidade do vento, o valor de $\mathrm{R}^{2}$ aumenta. Assim, na Figura 9, para médias diárias de velocidade do vento (Figura 9a), tem-se o modelo de regressão

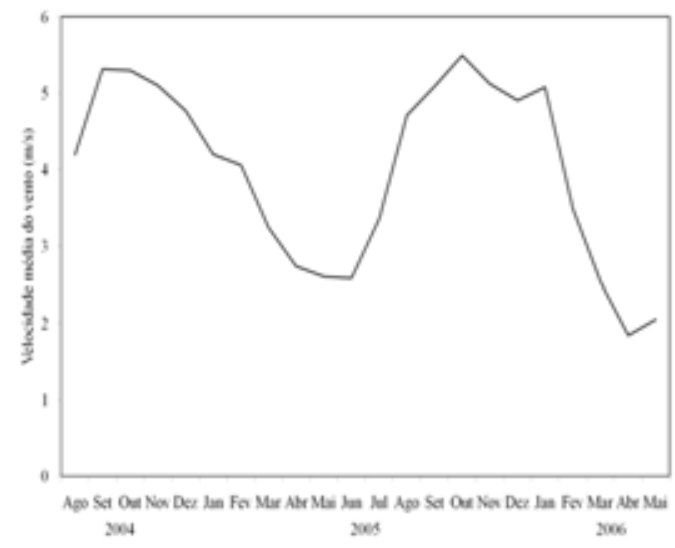

Figura 4 - Perfil mensal da velocidade do vento na PCD de São Gonçalo do Amarante. 


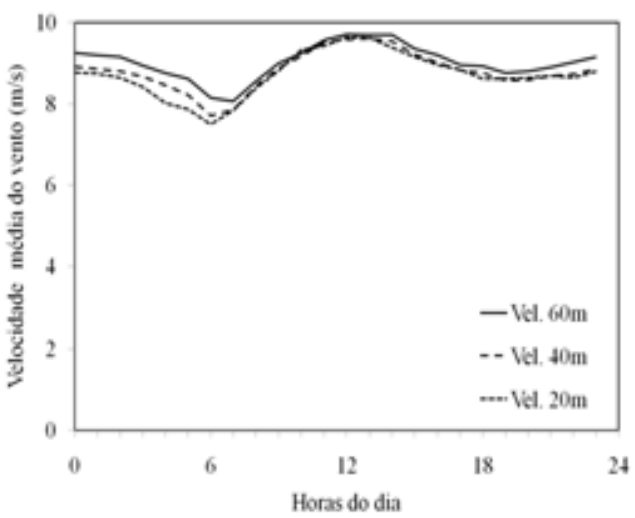

Figura 5. Perfil diário da velocidade do vento na TA de Paracuru.

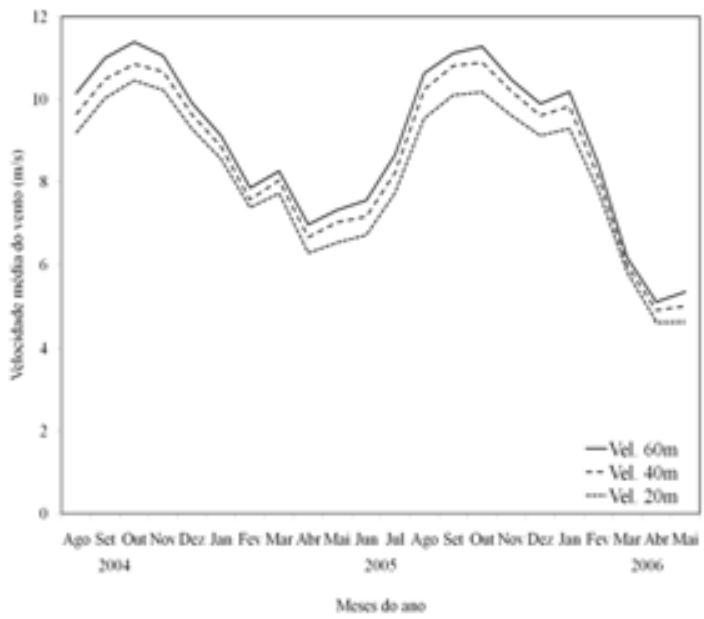

Figura 6. Médias mensais da velocidade do vento na TA de Paracuru.

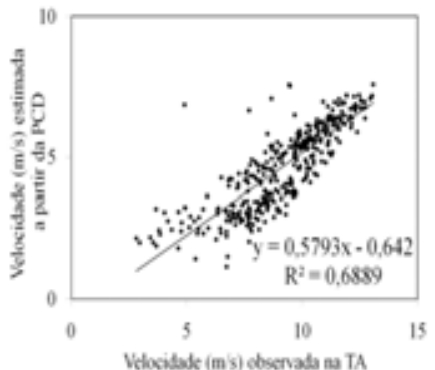

(a)

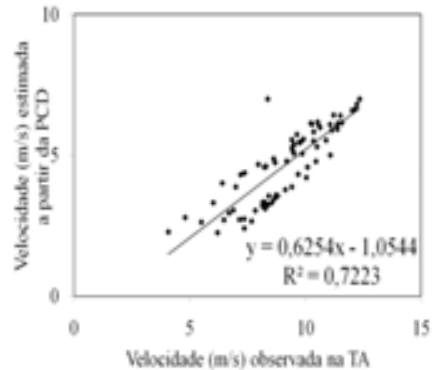

(b)

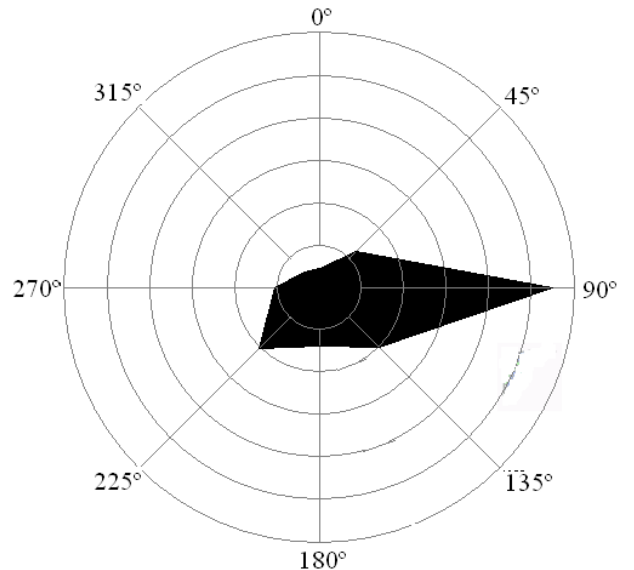

Figura 7 - Direção predominante do vento à $10 \mathrm{~m}$ na PCD de São Gonçalo do Amarante.

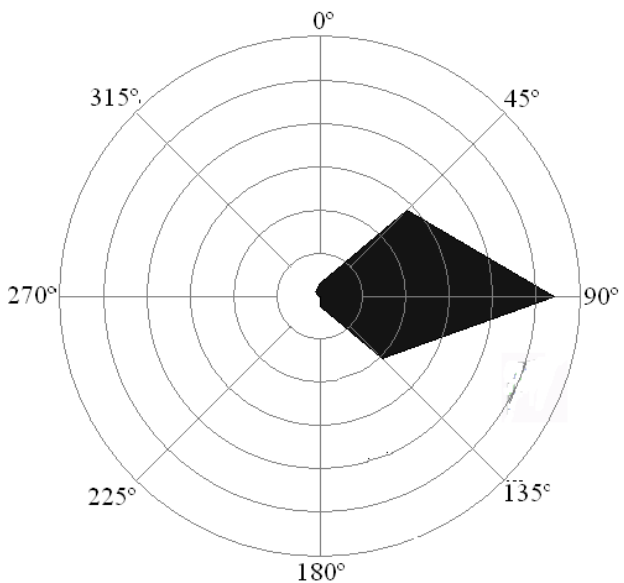

Figura 8 - Direção predominante do vento à $60 \mathrm{~m}$ na TA de Paracuru.

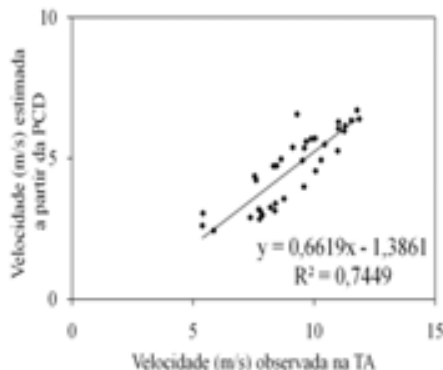

(c)

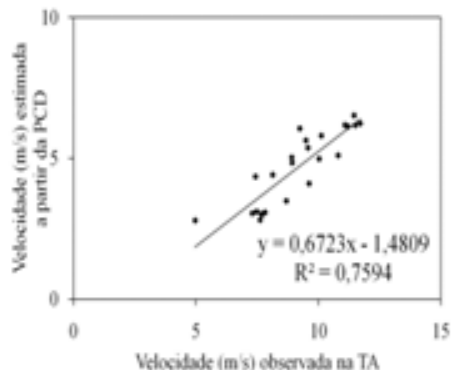

(d)

Figura 9 - Correlações entre os dados estimados pela PCD de SGA para 60m (eixo das ordenadas) e os dados observados à 60m na TA de Paracuru (eixo das abscissas) obtidas para médias diárias (a), de 5 (b), de 10 (c) e de 15 dias (d).

linear explicando aproximadamente $69 \%$ da variabilidade dos dados observados, enquanto que para médias de 15 dias (Figura 9d) o modelo explica aproximadamente $76 \%$ dessa variabilidade.

Na Figura 10, observa-se que o modelo explica aproximadamente $70 \%$ da variabilidade dos dados observados, quando se utilizam médias diárias, sendo que esse percentual chega a valores próximos de 79\% para médias de 15 dias (Figura 10d).
Já na Figura 11, o modelo explica 74\% (Figura 11a) e $84 \%$ (Figura 11d) da variabilidade dos dados observados quando o período de cálculo das médias é respectivamente, diário e de 15 dias.

Para verificar se as variâncias entre as amostras da TA e as estimativas da PCD eram homogêneas, realizou-se um teste de homogeneidade da variância entre elas utilizando-se o 


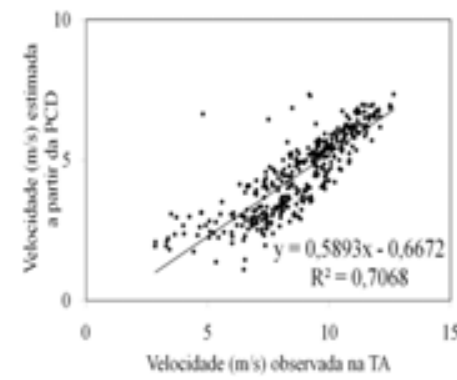

(a)

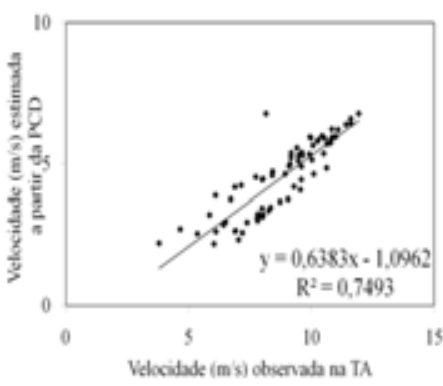

(b)

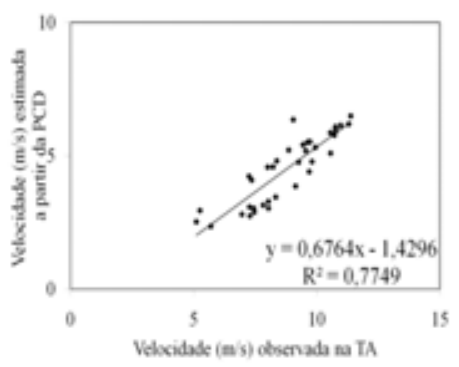

(c)

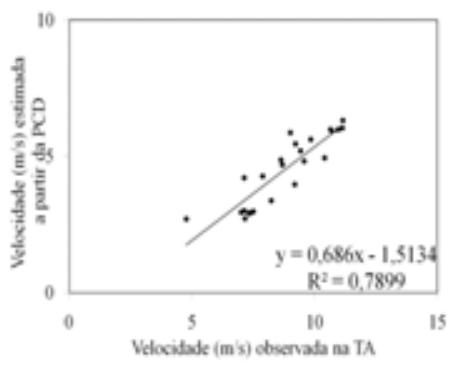

(d)

Figura 10 - Correlações entre os dados estimados pela PCD de SGA para 40m (eixo das ordenadas) e os dados observados à 40m na TA de Paracuru (eixo das abscissas) obtidas para médias diárias (a), de 5 (b), de 10 (c) e de 15 dias (d).

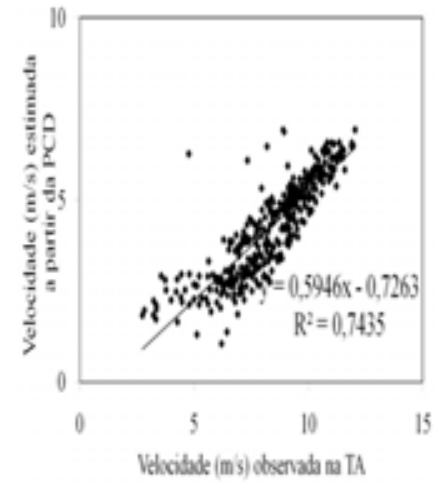

(a)

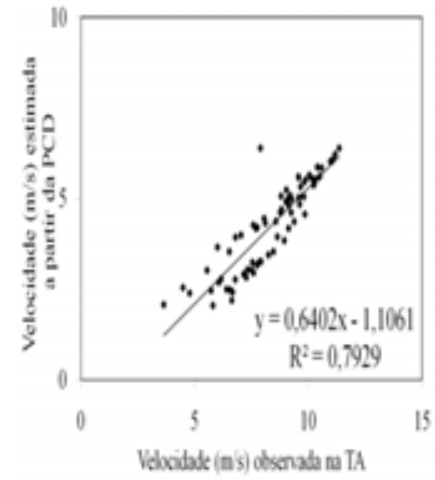

(b)

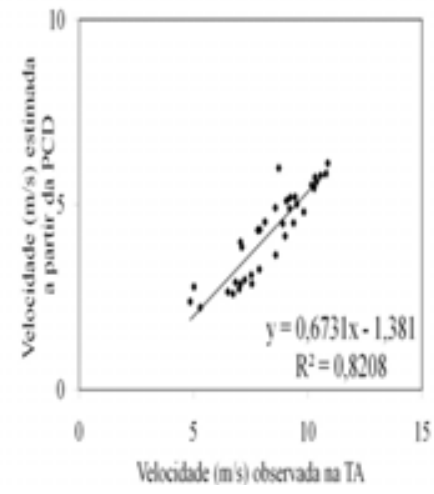

(c)

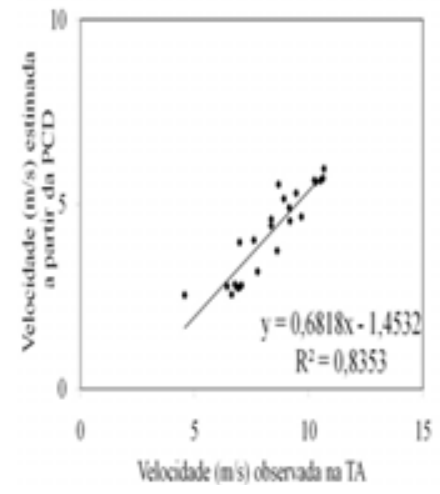

(d)

Figura 11 - Correlações entre os dados estimados pela PCD de SGA para 20m (eixo das ordenadas) e os dados observados à 20m na TA de Paracuru (eixo das abscissas) obtidas para médias diárias (a), de 5 (b), de 10 (c) e de 15 dias (d).

software Minitab ${ }^{\circledR}$ versão 15 (versão para teste). Além disso, nesta figura é mostrado um intervalo de confiança para desvios padrões segundo o teste de Bonferroni. A Figura 12 mostra os resultadosdeste teste utilizando-se dois métodos: Bartlett e Levene. O valor de $P>0,05$ (embora no teste de Levene $P=0,049$ para a amostra estimada, pode-se considerar esta aproximação sem prejuízo para o teste) portanto, não rejeita-se a hipótese $\mathrm{H}_{0}$, ou seja, a variância das amostras são homogêneas.

Após a obtenção das equações das retas que representam o ajuste de regressão linear entre os conjuntos de dados de velocidade do vento, mostrados anteriormente, procedimento denominado calibração, foram obtidos valores estimados por essas retas para as três alturas de medição da TA de Paracuru, e assim, foram comparados com os conjuntos de dados observados na TA, visando investigar o desempenho do modelo de regressão linear em reproduzir a variabilidade da velocidade média do vento observada na região de Paracuru a partir das velocidades médias estimadas, pelo perfil logarítmico do vento, obtido dos dados de velocidade do vento observados na PCD de SGA.

Na Figura 13 mostra-se a comparação entre as séries de dados estimados pelo método de regressão linear e os observados na TA de Paracuru, para médias diárias, de 5, de 10 e de 15 dias, na altura de 60 metros.

Nessa figura observa-se uma concordância entre os valores de velocidades médias estimadas e observadas em todos os períodos de cálculo de médias investigados. Em geral, a série de dados obtidos pelo modelo de regressão linear superestima a série dos dados observados, na estação seca, e subestima na estação chuvosa. Essa observação fica mais evidente, quando se aumenta o período de cálculo das médias de velocidades do vento.

Na Figura 14 tem-se a comparação entre as séries de dados estimados pelo método de regressão linear e os observados na TA de Paracuru, para médias diárias, de 5, de 10 e de 15 dias, na altura de 40 metros.

Os resultados apontam, novamente, períodos de subestimativa e superestimativa semelhantes aos citados na comparação anterior, para o caso de 60 metros de altura.

A Figura 15 mostra a comparação entre as séries de dados estimados pelo método de regressão linear e os observados na TA de Paracuru, para médias diárias, de 5, de 10 e de 15 dias, na altura de 20 metros. Nessa comparação, tem-se também superestimativas dos valores observados, no período seco e subestimativa no período chuvoso, concordando 
com as outras duas situações mostradas anteriormente, para 60 e 40 metros.

Essa característica, encontrada nessas comparações, se deve ao fato de que as séries de dados de velocidades do vento observado (TA), mostradas nas Figuras 5 e 6 terem comportamentos de variabilidade temporal semelhantes, diferindo apenas nos valores, que em 60 metros são maiores que em 40 metros, que por sua vez são maiores que os valores em 20 metros.

A Tabela 1 mostra para o período de calibração, os resultados da quantificação dos erros, bem como os valores dos coeficientes de correlação e determinação.

Em geral, para as três alturas, obtêm-se os menores valores de RMSE, MAE e $\varepsilon$ na comparação entre as séries de valores médios estimados e observados de 15 dias, onde também se verificam os maiores valores dos coeficientes de correlação e determinação.

Para se verificar o ajuste entre as duas séries foi realizado o teste de Kolmogorov-Smirnov (2003), que mostrou significância de $95 \%$.

\subsubsection{Período de validação - região de Paracuru}

Nesta seção serão descritos os resultados referentes ao período de validação, a fim de se investigar se o modelo de regressão linear apresenta desempenho satisfatório para estimativa dos valores médios da velocidade do vento na região de Paracuru.

Na Figura 16 têm-se a comparação entre as séries de dados estimados pelo método de regressão linear e os observados na TA de Paracuru, para médias diárias, de 5, de 10 e de 15 dias, na altura de 60 metros, para o período de validação.
Nesta figura verifica-se que, entre a série de dados estimados e a série de dados observados na TA de Paracuru, existe uma concordância ao longo de todo o período de validação, no qual predomina, em geral, a superestimativa dos dados obtidos pela regressão linear em relação aos dados observados na TA. Essa superestimativa concorda com os resultados encontrados no período de calibração, quando se considera o mesmo intervalo de tempo das séries de dados, agosto de um ano a maio do ano seguinte, que corresponde ao período seco dessa região. Essa característica fica mais evidente quando se aumenta o período de cálculo das médias das velocidades do vento.

A Figura 17 mostra a comparação entre as séries de dados obtidos pelo método de regressão linear e os observados na TA de Paracuru, para médias diárias, de 5 dias, de 10 dias e de 15 dias, na altura de 40 metros, no período em estudo.

Analisando-se essas figuras, verifica-se, em geral, a existência de uma superestimativa dos dados obtidos pela regressão linear em relação aos dados observados na TA, característica também encontrada no período de calibração para o mesmo intervalo de tempo (agosto a maio).

São mostradas na Figura 18 as comparações entre as séries de dados estimados e os observados na TA de Paracuru, para os mesmos intervalos de médias, na altura de 20 metros, no período de validação.

Assim, pode-se observar que, em geral, também ocorre a superestimativa da série de dados obtidos pela regressão em relação aos observados na TA, observada no mesmo intervalo de tempo no período de calibração, como se verifica nas comparações anteriores.

Assim como se procedeu no período de calibração, a fim de se avaliar o grau de ajuste entre os dados observados

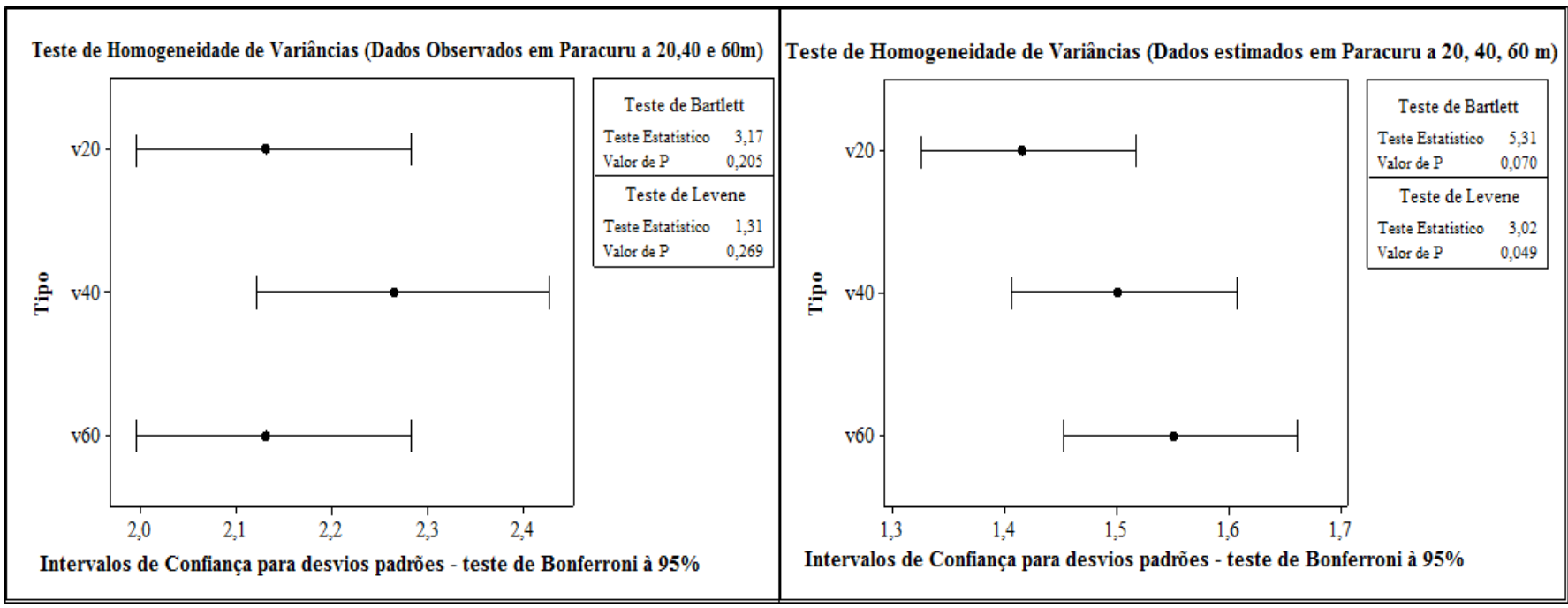

Figura 12 - Teste de homogeneidade de variância para a região de Paracuru: dados observados (12a) e dados estimados (12b). 


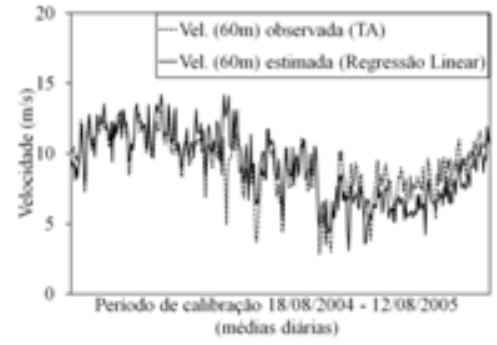

(a)

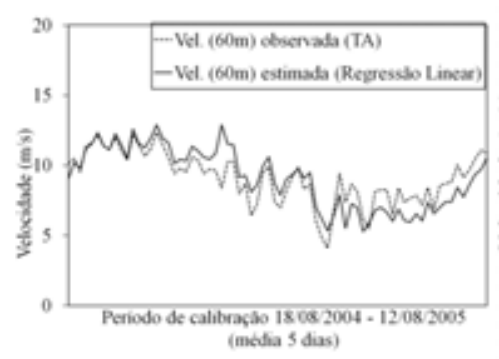

(b)

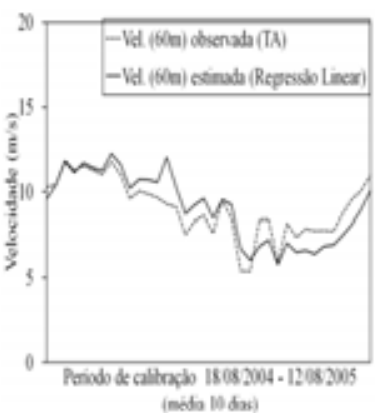

(c)

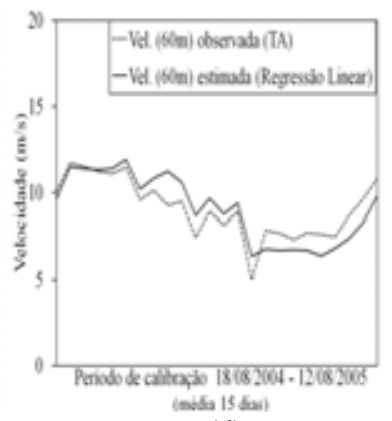

(d)

Figura 13 - Comparação entre as séries de dados estimados pela regressão linear e os dados observados na TA de Paracuru para a altura de 60 metros no período de calibração, para médias diárias (a), de 5 (b), de 10 (c) e de 15 dias (d).

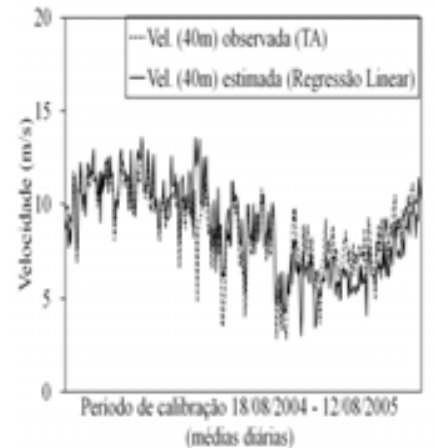

(a)

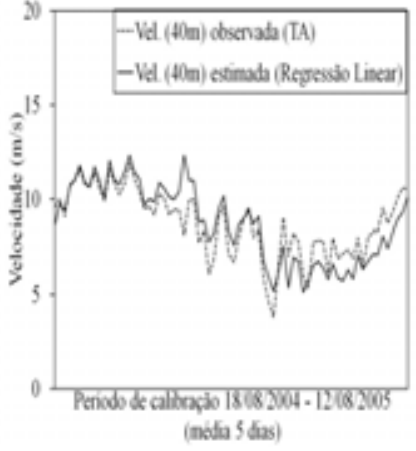

(b)

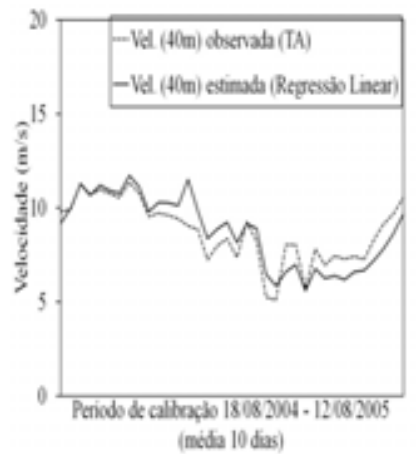

(c)

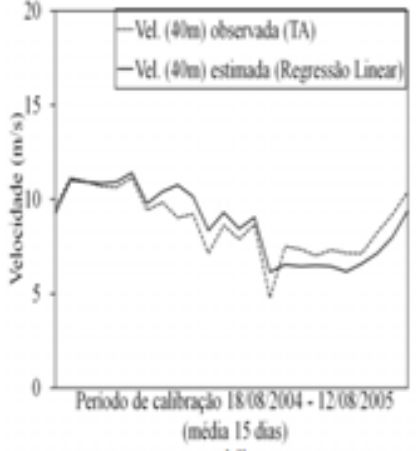

(d)

Figura 14 - Comparação entre as séries de dados estimados pela regressão linear e os dados observados na TA de Paracuru para a altura de 40 metros no período de calibração, para médias diárias (a), de 5 (b), de 10 (c) e de 15 dias (d).

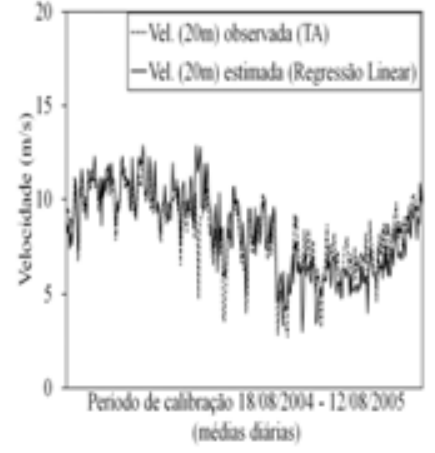

(a)

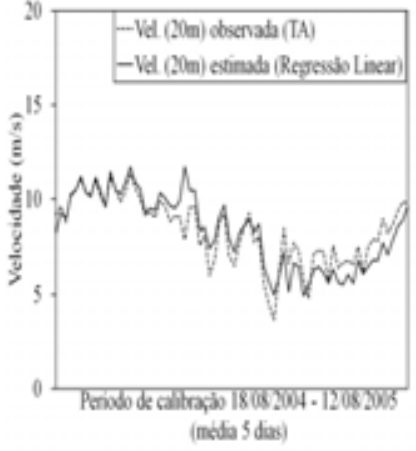

(b)

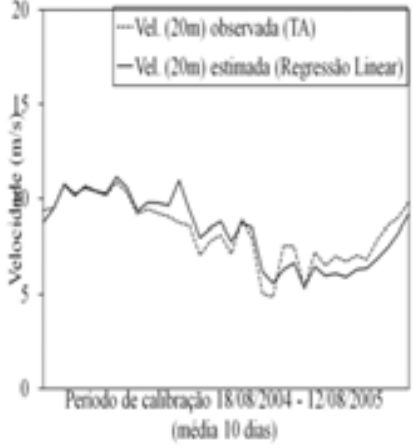

(c)

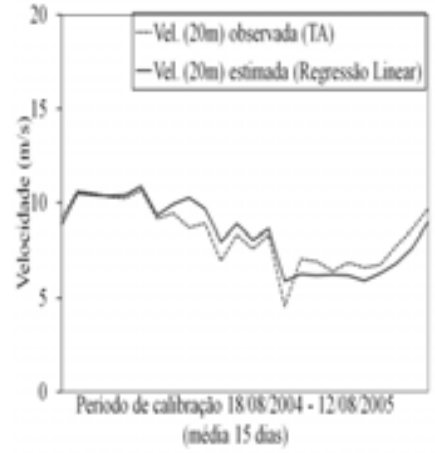

(d)

Figura 15 - Comparação entre as séries de dados estimados pela regressão linear e os dados observados na TA de Paracuru para a altura de 20 metros no período de calibração, para médias diárias (a), de 5 (b), de 10 (c) e de 15 dias (d).

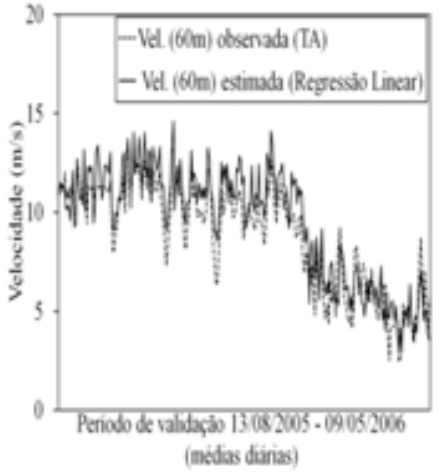

(a)

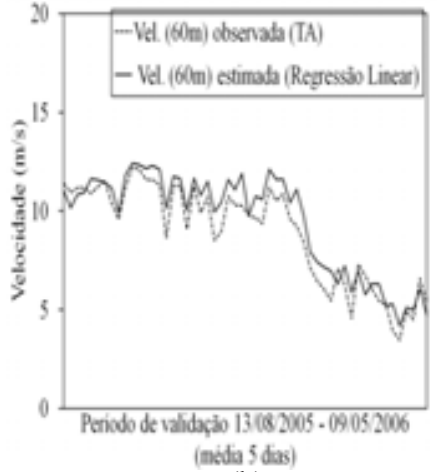

(b)

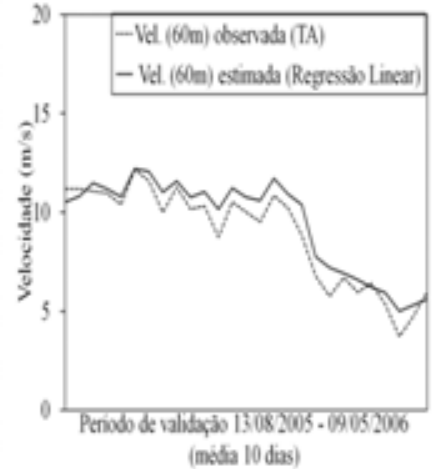

(c)

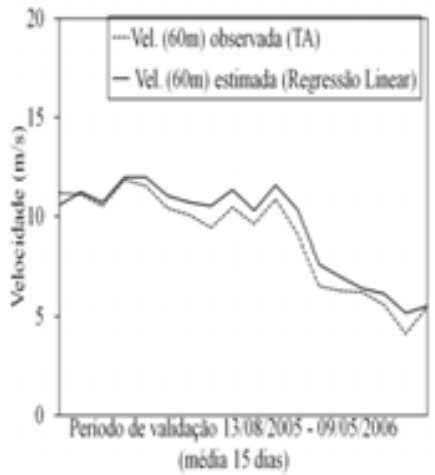

(d)

Figura 16 - Comparação entre as séries de dados estimados pela regressão linear e os dados observados na TA de Paracuru para a altura de 60 metros no período de validação, para médias diárias (a), de 5 (b), de 10 (c) e de 15 dias (d). 
Tabela 1 - Valores dos erros e coeficientes de correlação e determinação entre os dados estimados pelas equações das retas de regressão linear e os dados observados na TA de Paracuru no período de calibração.

\begin{tabular}{|c|c|c|c|c|c|c|}
\hline $\begin{array}{c}\text { Altura } \\
(\mathbf{m})\end{array}$ & $\begin{array}{l}\text { Períodos nos quais se obteve as } \\
\text { médias das velocidades do vento }\end{array}$ & $\begin{array}{c}\text { RMSE } \\
(\mathbf{m} / \mathbf{s})\end{array}$ & $\begin{array}{l}\text { MAE } \\
(\mathbf{m} / \mathbf{s})\end{array}$ & $\begin{array}{c}\varepsilon \\
(\%)\end{array}$ & $\mathbf{r}$ & $\overline{\mathbf{R}^{2}}$ \\
\hline \multirow{4}{*}{$\underset{\text { సิ }}{\Xi}$} & Diárias & 1,12 & 0,86 & 0,10 & 0,86 & 0,74 \\
\hline & 5 dias & 0,87 & 0,68 & 0,02 & 0,89 & 0,79 \\
\hline & 10 dias & 0,75 & 0,60 & 0,02 & 0,91 & 0,83 \\
\hline & 15 dias & 0,70 & 0,58 & 0,11 & 0,91 & 0,83 \\
\hline \multirow{4}{*}{$\stackrel{\Xi}{\ominus}$} & Diárias & 1,29 & 1,01 & 0,04 & 0,84 & 0,71 \\
\hline & 5 dias & 1,02 & 0,82 & 0,04 & 0,87 & 0,76 \\
\hline & 10 dias & 0,88 & 0,73 & 0,05 & 0,88 & 0,77 \\
\hline & 15 dias & 0,83 & 0,71 & 0,01 & 0,89 & 0,79 \\
\hline \multirow{4}{*}{$\underset{\Xi}{\Xi}$} & Diárias & 1,39 & 1,10 & 0,06 & 0,83 & 0,69 \\
\hline & 5 dias & 1,13 & 0,92 & 0,06 & 0,85 & 0,72 \\
\hline & 10 dias & 0,99 & 0,84 & 0,13 & 0,86 & 0,74 \\
\hline & 15 dias & 0,94 & 0,82 & 0,02 & 0,87 & 0,76 \\
\hline
\end{tabular}

e estimados, no período de validação, também foram quantificados os erros RMSE, MAE e $\varepsilon$. Calcularam-se também os coeficientes de correlação e determinação entre os dois conjuntos de dados. Os resultados dessas quantificações são mostrados na Tabela 2.

Para 20 metros, observa-se que os menores valores de RMSE, MAE e $\varepsilon$ foram respectivamente, $0,66 \mathrm{~m} / \mathrm{s}, 0,59 \mathrm{~m} / \mathrm{s}$ e 6,3\% nas comparações entre os valores médios de 15 dias.

Ainda nessa altitude o coeficiente máximo de correlação foi de 0,99 para médias de 15 dias e o coeficiente máximo de determinação explica $98 \%$ da variabilidade dos dados observados.

Em 40 metros, os menores valores de RMSE, MAE e $\varepsilon$ foram respectivamente, $0,66 \mathrm{~m} / \mathrm{s}, 0,56 \mathrm{~m} / \mathrm{s}$ e $5,3 \%$, todos registrados nas comparações entre os valores médios de 15 dias, em que o coeficiente de correlação foi máximo $(0,98)$ e o coeficiente de determinação indica que $96 \%$ da variabilidade dos dados observados foi capturada. Para 60 metros, os menores valores dos erros acima citados foram respectivamente, 0,72 $\mathrm{m} / \mathrm{s}, 0,62 \mathrm{~m} / \mathrm{s}$ e $5,8 \%$, todos registrados nas comparações entre os valores médios de 15 dias, onde se tem também o coeficiente máximo de correlação observado $(0,98)$ e o coeficiente máximo de determinação que explica $96 \%$ da variabilidade dados observados.

Tanto para o período de calibração, quanto para o de validação, os valores de RMSE e MAE são inferiores aos erros encontrados por Santiago de Maria et al (2006), quando o mesmo comparou os valores de velocidade média do vento observados na TA de Paracuru com os valores simulados com o RAMS a 20, 40 e 60 metros. Adicionalmente, os valores dos coeficientes de correlação aqui apresentados em ambos os períodos são superiores aos valores encontrados pelo autor acima citado.

\subsection{Resultados para a região de Camocim}

\subsubsection{Caracterização do regime de ventos na região de Camocim}

As Figuras 19 e 20 mostram, respectivamente, o perfil médio diário e mensal da velocidade do vento, a partir de dados coletados na PCD de BAR.

Em relação ao perfil de velocidade média diária do vento, observa-se que os maiores valores de velocidade média do vento ocorrem no período diurno, compreendido entre $06: 00 \mathrm{~h}$ e 18:00h horário local, com valor máximo de $6,2 \mathrm{~m} / \mathrm{s}$ registrado por volta de 14:00h. Estes resultados estão diretamente ligados à presença de brisas marítimas, como já foi exposto nos estudos de Molion e Bernardo (2000) e de Barreto et al. (2002).

Já para o perfil de velocidade média mensal do vento, no período compreendido entre os meses de agosto e dezembro, se verificam os maiores valores de velocidade média do vento. Assim como na região de Paracuru, esse período coincide com a estação seca da região. Por outro lado, os menores valores são observados no período de estação chuvosa da região, mais precisamente entre os meses de fevereiro a maio.

As Figuras 21 e 22 mostram, respectivamente, o perfil médio diário e mensal da velocidade do vento na TA de Camocim.

Para o perfil diário de velocidade média do vento, observa-se a ocorrência dos maiores valores de velocidade média do vento, aproximadamente da ordem de $12,0 \mathrm{~m} / \mathrm{s}$, em torno da 17:00h horário local.

Considerando-se o perfil mensal de velocidade média, os períodos onde se verifica os maiores e os menores índices de velocidade média do vento, coincide com os mesmos períodos de ocorrência na PCD de BAR, ou seja, respectivamente com a estação seca e com a estação chuvosa da região. Observa-se 


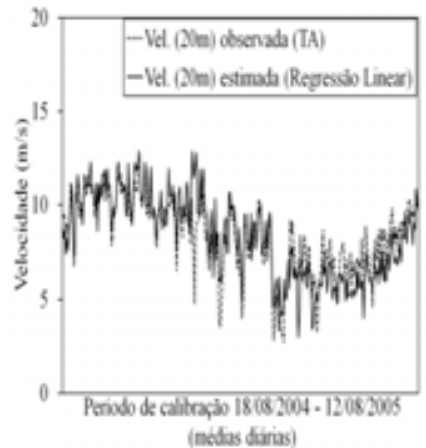

(a)

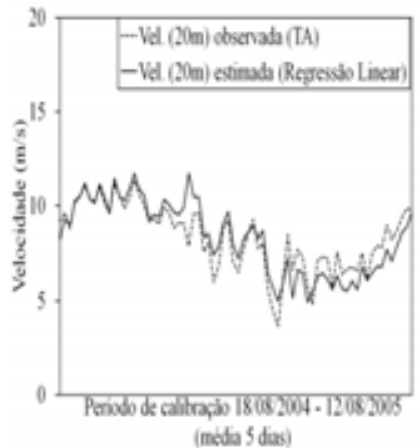

(b)

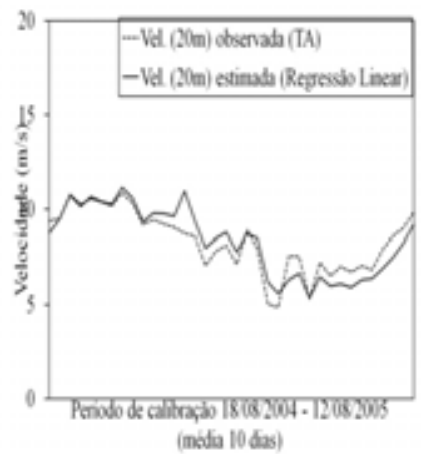

(c)

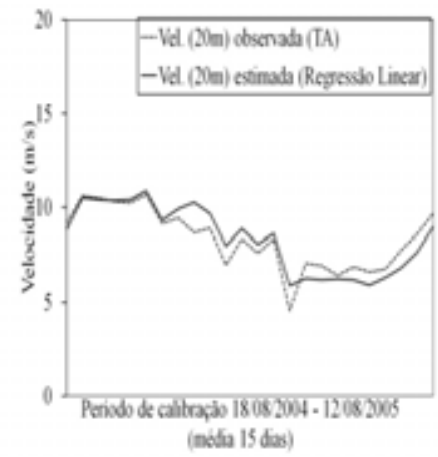

(d)

Figura 17 - Comparação entre as séries de dados estimados pela regressão linear e os dados observados na TA de Paracuru para a altura de 40 metros no período de validação, para médias diárias (a), de 5 (b), de 10 (c) e de 15 dias (d).

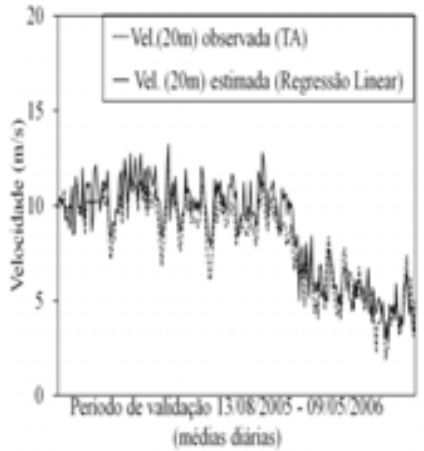

(a)

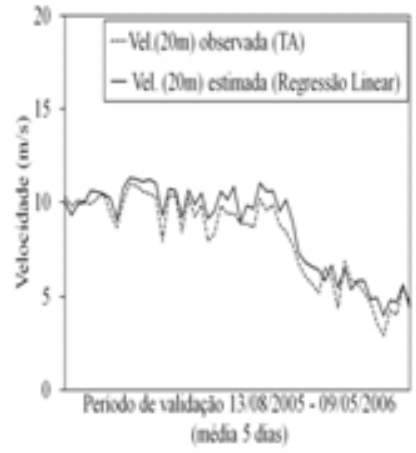

(b)

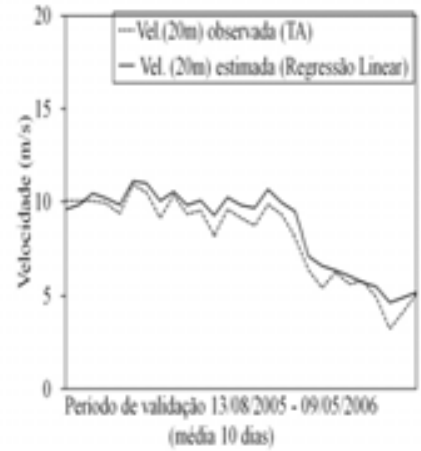

(c)

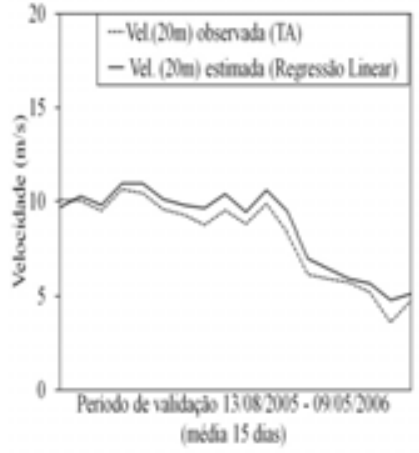

(d)

Figura 18 - Comparação entre as séries de dados estimados pela regressão linear e os dados observados na TA de Paracuru para a altura de 40 metros no período de validação, para médias diárias (a), de 5 (b), de 10 (c) e de 15 dias (d).

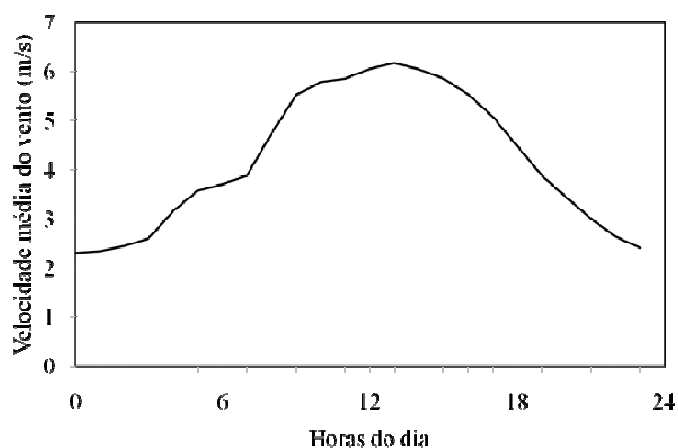

Figura 19 - Perfil diário da velocidade do vento na PCD de Barroquinha.

ainda que todos os valores médios mensais estão acima de 2,5 $\mathrm{m} / \mathrm{s}$, velocidade de entrada dos aerogeradores.

As Figuras 23 e 24 apresentam a direção predominante do vento na PCD de BAR e a direção predominante do vento na TA de Camocim. Em ambas as figuras observa-se que a direção predominante do vento é de leste, com variações entre as direções de nordeste e sudoeste. Essas observações evidenciam a influência dos Ventos Alísios conforme exposto por Barreto et al. (2002).

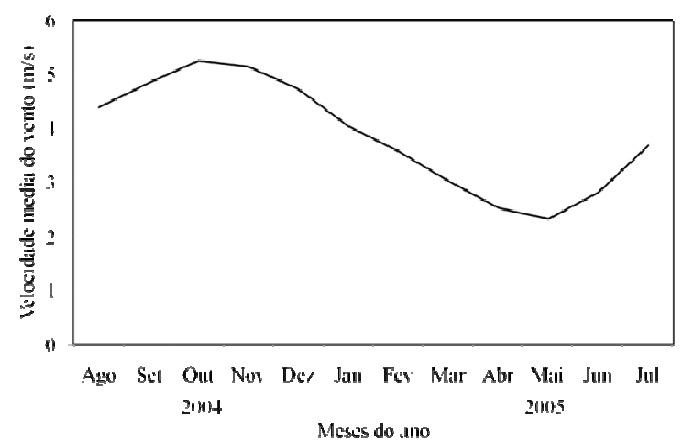

Figura 20 - Médias mensais da velocidade do vento na PCD de Barroquinha.

\subsubsection{Período de calibração - região de Camocim}

As Figuras 25, 26 e 27 apresentam as correlações entre os valores de velocidade média do vento estimados para 60,40 e 20 metros, respectivamente, através dos dados observados em superfície na PCD de BAR, e os valores observados na TA de Camocim.

Em adição, nessas figuras têm-se as equações das retas correspondentes aos ajustes de regressão linear juntamente 
Tabela 2 - Valores dos erros e coeficientes de correlação e determinação entre os dados estimados na TA pelas equações das retas de regressão e os dados observados na TA no período de validação para a região de Paracuru.

\begin{tabular}{|c|c|c|c|c|c|c|}
\hline $\begin{array}{c}\text { Altura } \\
(\mathbf{m})\end{array}$ & $\begin{array}{l}\text { Períodos nos quais se obteve as } \\
\text { médias das velocidades do vento }\end{array}$ & $\begin{array}{c}\text { RMSE } \\
(\mathbf{m} / \mathbf{s})\end{array}$ & $\begin{array}{l}\text { MAE } \\
(\mathbf{m} / \mathbf{s})\end{array}$ & $\begin{array}{c}\varepsilon \\
(\%) \\
\end{array}$ & $\mathbf{R}$ & $\mathbf{R}^{2}$ \\
\hline \multirow{4}{*}{$\stackrel{\text { Iิ }}{\Xi}$} & Diárias & 1,02 & 0,85 & 6,8 & 0,95 & 0,90 \\
\hline & 5 dias & 0,77 & 0,67 & 6,4 & 0,97 & 0,94 \\
\hline & 10 dias & 0,70 & 0,60 & 6,3 & 0,98 & 0,96 \\
\hline & 15 dias & 0,66 & 0,59 & 6,3 & 0,99 & 0,98 \\
\hline \multirow{4}{*}{$\stackrel{g}{\stackrel{g}{q}}$} & Diárias & 1,07 & 0,89 & 5,9 & 0,94 & 0,88 \\
\hline & 5 dias & 0,80 & 0,69 & 5,6 & 0,97 & 0,94 \\
\hline & 10 dias & 0,72 & 0,60 & 5,4 & 0,98 & 0,96 \\
\hline & 15 dias & 0,66 & 0,56 & 5,3 & 0,98 & 0,96 \\
\hline \multirow{4}{*}{$\stackrel{8}{\Xi}$} & Diárias & 1,17 & 0,99 & 6,6 & 0,94 & 0,88 \\
\hline & 5 dias & 0,88 & 0,77 & 6,1 & 0,97 & 0,94 \\
\hline & 10 dias & 0,79 & 0,68 & 6,0 & 0,97 & 0,94 \\
\hline & 15 dias & 0,72 & 0,62 & 5,8 & 0,98 & 0,96 \\
\hline
\end{tabular}

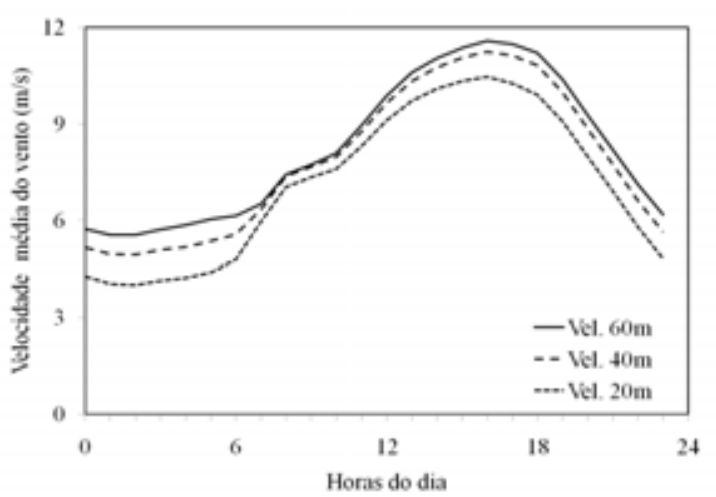

Figura 21 - Perfil diário da velocidade do vento na TA de Camocim. Barroquinha.

com os coeficientes de determinação $\left(\mathrm{R}^{2}\right)$ obtidos para médias diárias, de 5, de 10 e de 15 dias. As figuras também mostram que, assim como ocorre para a região de Paracuru, na medida em que se aumenta o período de cálculo das médias de velocidade do vento, o coeficiente de determinação aumenta.

Assim, na Figura 25, onde foram realizadas análises para a altura de 60 metros, para médias diárias de velocidade do vento (Figura 25a), tem-se o modelo de regressão linear explicando aproximadamente $82 \%$ da variabilidade dos dados observados, enquanto que para médias de 15 dias (Figura 25d) o modelo explica aproximadamente $93 \%$ dessa variabilidade.

Na Figura 26, que mostra os resultados obtidos para 40 metros, observa-se que, enquanto para médias diárias (Figura 26a) o modelo explica $82 \%$ da variabilidade dos dados observados, tem-se para médias de 15 dias (Figura 26d) o modelo explicando $94 \%$ dessa variabilidade.

Para 20 metros de altura, os resultados obtidos são mostrados na Figura 27. Observa-se que, para médias diárias (Figura 27a) e médias de 15 dias (Figura 27d), o modelo explica, respectivamente, $83 \%$ e $95 \%$ da variabilidade dos dados observados.

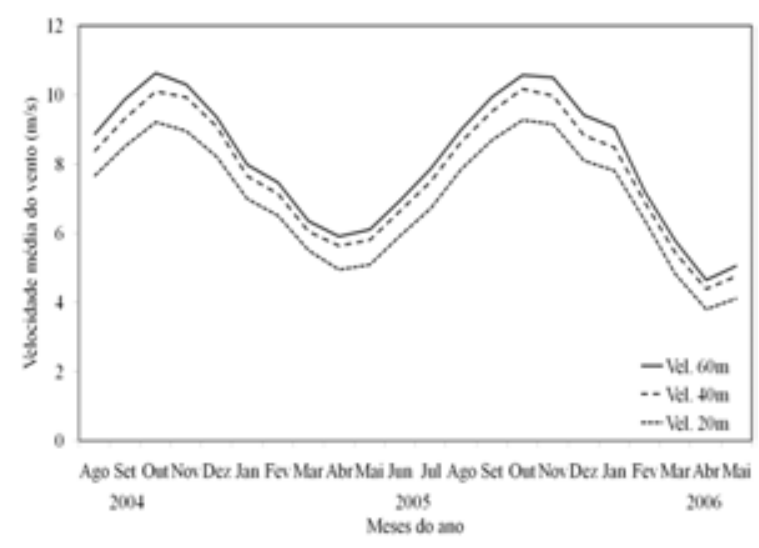

Figura 22 - Médias mensais da velocidade do vento na TA de Camocim.

Também para esta região realizou-se um teste de homogeneidade da variância entre as amostras. A Figura 28 mostra o resultado deste teste utilizando-se dois métodos: Bartlett e Levene. Além disso, esta figura mostra um intervalo de confiança para desvios padrões segundo o teste de Bonferroni. No teste, para os valores observados obteve-se $P<0,05$ e assim rejeita-se a hipótese $\mathrm{H}_{0}$,ou seja, a variância das amostras não são homogêneas, mas os valores obtidos ( $P=0,045$ e $P=0,044)$ estão tão próximos de 0,05 que é razoável aceitá-los. Uma explicação para a obtenção destes valores baseia-se no fato de que na região de Camocim, o número de amostras foi inferior àquelas tratadas em Paracuru, além do que nas amostras observadas identificaram-se muitos dados inconsistentes e mesmo inexistentes, que foram corrigidos pelo método de preenchimento de falhas já citado.

Assim como se procedeu para a região de Paracuru, após a obtenção das equações das retas que representam o ajuste de regressão linear entre os conjuntos de dados de velocidade do vento, mostrados anteriormente, na calibração, foram obtidos valores estimados por essas retas para as três alturas de medição da TA de Camocim, e assim, foram comparados aos conjuntos de dados observados na mesma. 


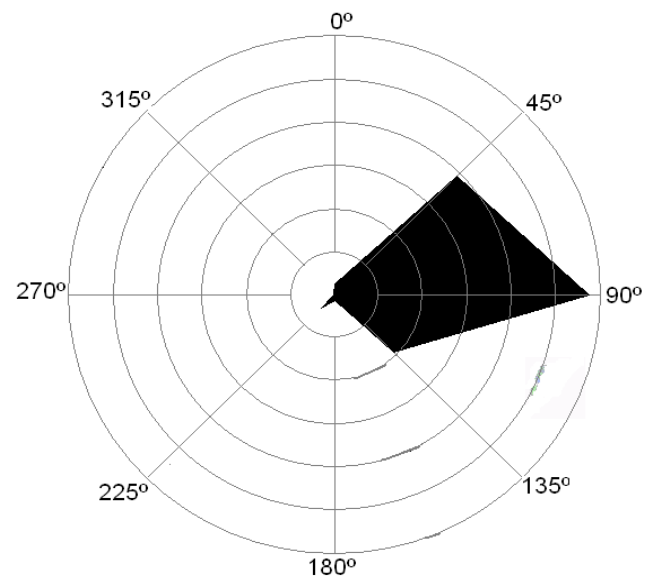

Figura 23 - Direção predominante do vento à $10 \mathrm{~m}$ na $\mathrm{PCD}$ de Barroquinha.

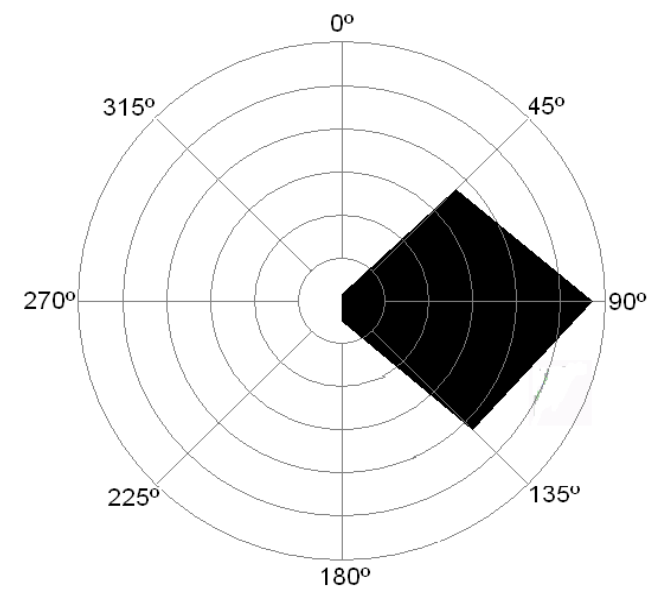

Figura 24 - Direção predominante do vento à $60 \mathrm{~m}$ na TA de Camocim.

Na Figura 29 têm-se a comparação entre as séries de dados obtidos pelo método de regressão linear e os observados na TA de Camocim, para médias diárias, de 5 , de 10 e de 15 dias, na altura de 60 metros. Assim como, observou-se na região de Paracuru, a série de dados obtida pelo modelo de regressão linear, em geral, superestima a série dos dados observados, na estação seca da região e subestima na estação chuvosa.

Na Figura 30 tem-se a comparação entre as séries de dados obtidos pelo método de regressão linear e os observados na TA de Camocim, para médias diárias, de 5 , de 10 e de 15 dias,na altura de 40 metros. Os resultados indicam, novamente, períodos de subestimativa e superestimativa semelhantes aos citados na comparação anterior.

A Figura 31 mostra a comparação entre as séries de dados estimados pelo método de regressão linear e os observados na TA de Camocim, para médias diárias, de 5 , de 10 e de 15 dias, na altura de 20 metros. Nessa comparação, também se têm superestimativas dos valores observados no período seco e subestimativas no período chuvoso, concordando, dessa forma, com o que fora mostrado nas comparações anteriores, para 60 e 40 metros.

A quantificação dos erros foi feita pelos mesmos métodos utilizados para a região de Paracuru. A Tabela 3 mostra para o período de calibração, os resultados dessa quantificação, bem como os valores dos coeficientes de correlação e determinação.

Os valores dos erros são menores e os coeficientes de determinação maiores se comparados com os erros para o período de calibração da região de Paracuru.

Para as estimativas a 20 metros de altura, os menores valores de RMSE, MAE e $\varepsilon$ foram respectivamente, $0,36 \mathrm{~m} / \mathrm{s}$, $0,28 \mathrm{~m} / \mathrm{s}$ e $0,06 \%$, todos registrados para a comparação entre as séries de valores médios estimados e observados de 15 dias.

Ainda nessa altitude, o coeficiente máximo de correlação foi de 0,97 para a comparação entre as séries de valores médios estimados e observados de 10 e de 15 dias e o coeficiente máximo de determinação explica $94 \%$ da variabilidade dados observados.

Nas estimativas a 40 metros, os menores valores de RMSE, MAE e $\varepsilon$ foram respectivamente, $0,40 \mathrm{~m} / \mathrm{s}, 0,30 \mathrm{~m} / \mathrm{s}$ e $0,02 \%$, todos registrados para a comparação entre as séries de valores médios estimados e observados de 15 dias, em que se tem também coeficiente máximo de correlação $(0,97)$ e o coeficiente máximo de determinação explicando $94 \%$ da variabilidade dos dados observados.

Em 60 metros, os menores valores dos erros acima citados foram respectivamente, $0,42 \mathrm{~m} / \mathrm{s}, 0,33 \mathrm{~m} / \mathrm{s}$ e $0,03 \%$. Os dois primeiros registrados para o período de cálculo de 15 dias e o último para 10 dias. A 60 metros, também ocorre o valor máximo do coeficiente de correlação $(0,97)$, e o coeficiente máximo de determinação explica $94 \%$ da variabilidade dos dados observados.

Para a região de Camocim também foi realizado o teste de Kolmogorov-Smirnov (2003), que mostrou significância de 95\%.

\subsubsection{Período de validação - região de Camocim}

Na Figura 32 têm-se a comparação, no período de validação entre as séries de dados obtidos pelo método de regressão linear e os observados na TA de Camocim, para médias diárias, de 5 , de 10 e de 15 dias, na altura de 60 metros. Nessa figura observa-se que, em geral, a série de dados obtida pelo modelo de regressão linear, em geral, superestima a série dos dados observados na TA, tornando-se mais evidente na medida em que se aumenta o período das médias de velocidades do vento.

Esses resultados estão de acordo com os apresentados no período de calibração, quando também se tinha superestimativa nos mesmos intervalos de tempo, correspondente à estação seca da região.

A Figura 33 mostra a comparação entre as séries de dados obtidos pelo método de regressão linear e os observados na TA 


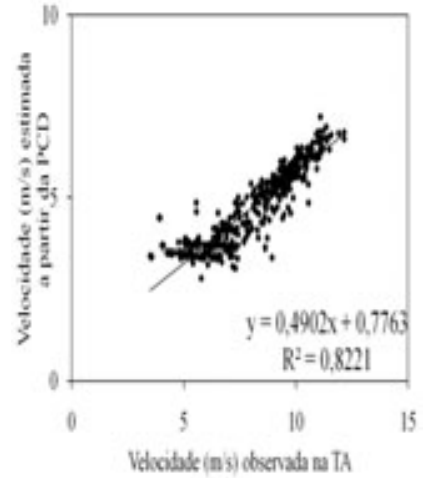

(a)

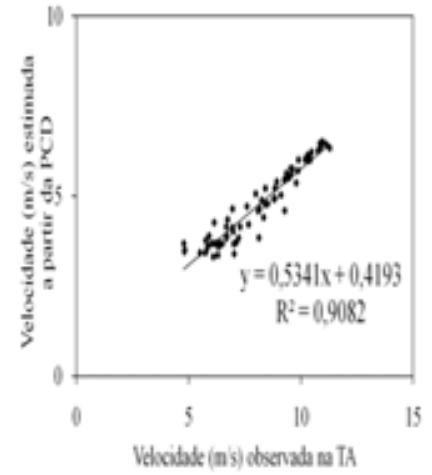

(b)

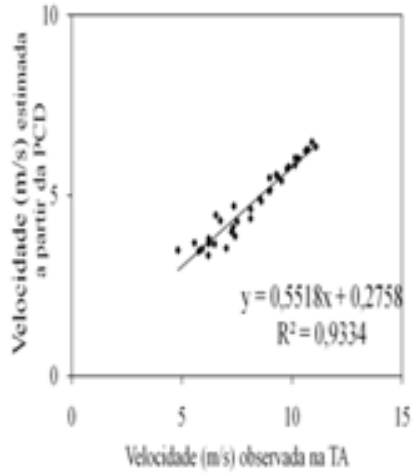

(c)

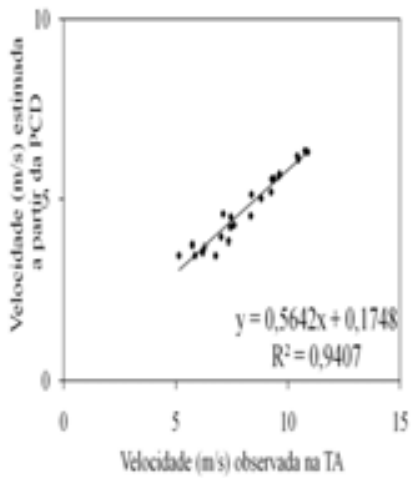

(d)

Figura 25 - Correlações entre os dados estimados pela PCD de BAR para 60m (eixo das ordenadas) e os dados observados à 60m na TA de Camocim (eixo das abscissas) obtidas para médias diárias (a), de 5 (b), de 10 (c) e de 15 dias (d).

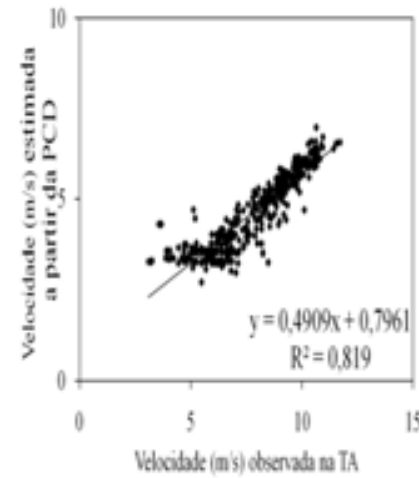

(a)

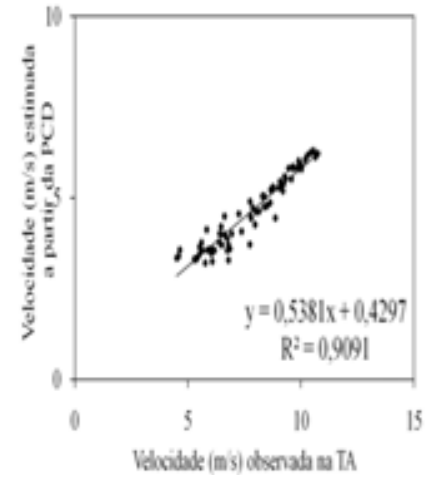

(b)

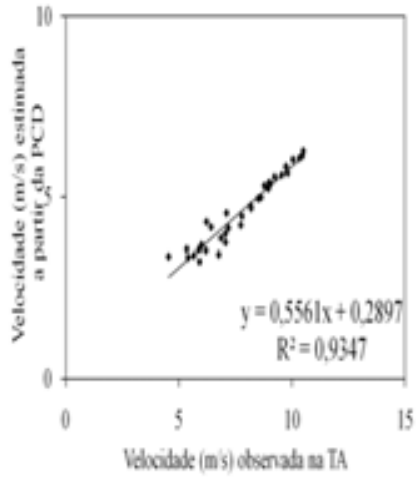

(c)

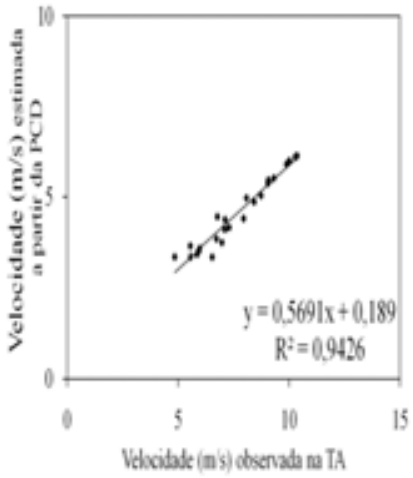

(d)

Figura 26 - Correlações entre os dados estimados pela PCD de BAR para 40m (eixo das ordenadas) e os dados observados à 40m na TA de Camocim (eixo das abscissas) obtidas para médias diárias (a), de 5 (b), de 10 (c) e de 15 dias (d).

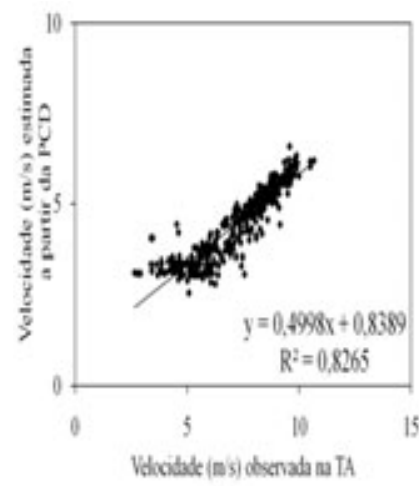

(a)

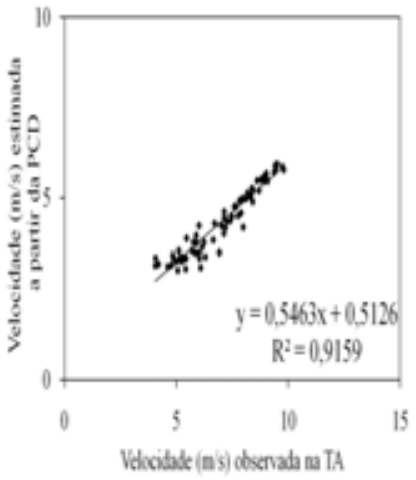

(b)

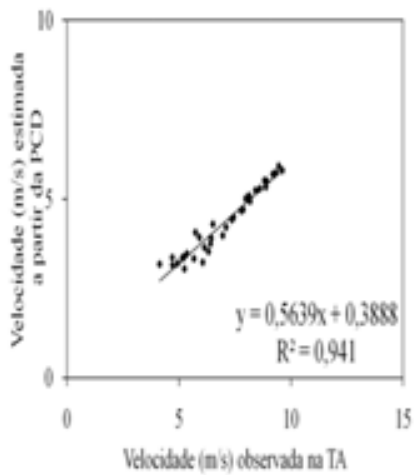

(c)

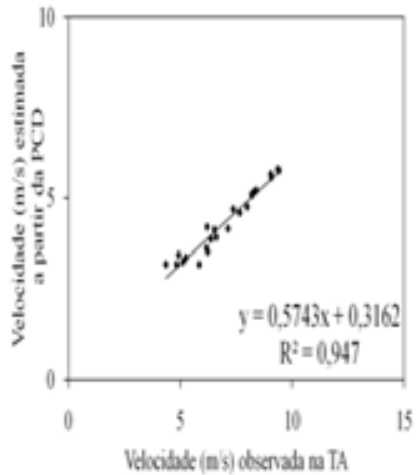

(d)

Figura 27 - Correlações entre os dados estimados pela PCD de BAR para 20m (eixo das ordenadas) e os dados observados à 20m na TA de Camocim (eixo das abscissas) obtidas para médias diárias (a), de 5 (b), de 10 (c) e de 15 dias (d).

de Camocim, para médias diárias, de 5 , de 10 e de 15 dias, na altura de 40 metros. Analisando-se essa figura, verifica-se também a indicação de superestimativas e subestimativas das séries de dados observados, nos mesmos intervalos de tempo verificados para o período de calibração.

Na Figura 34 são mostradas as comparações entre as séries de dados obtidos pelo método de regressão linear e os observados na TA de Camocim, na altura de 20 metros. Nota-se, em geral, boa concordância entre as séries de dados estimados e observados, nos mesmos intervalos de tempo onde ocorrem superestimativa e subestimativa no período de calibração.

Adicionalmente para o período de validação, avaliou-se o grau de ajuste entre os dados observados e estimados, quantificando 


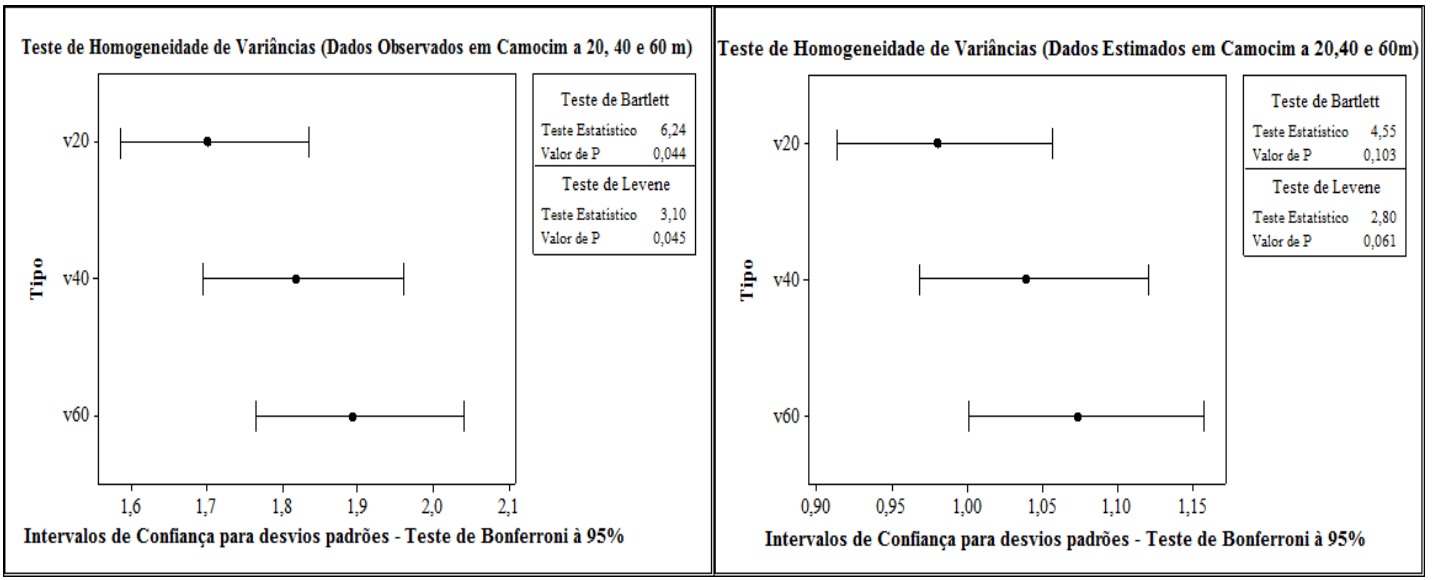

Figura 28 - Teste de homogeneidade de variância para a região de Camocim: dados observados (28a) e dados estimados (28b).

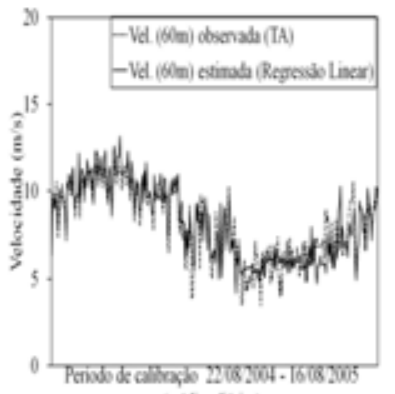

(a)

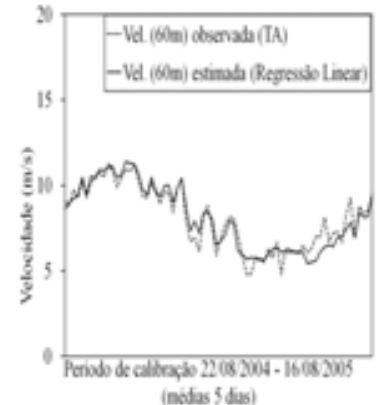

(b)

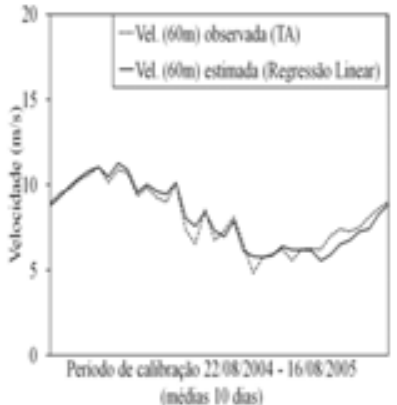

(c)

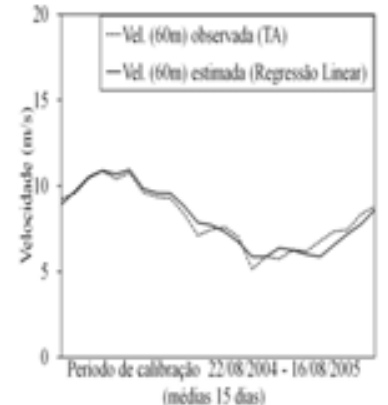

(d)

Figura 29 - Comparação entre as séries de dados estimados pela regressão linear e os dados observados na TA de Camocim para a altura de 60 metros no período de calibração, para médias diárias (a), de 5(b), de 10(c) e de 15 dias (d).

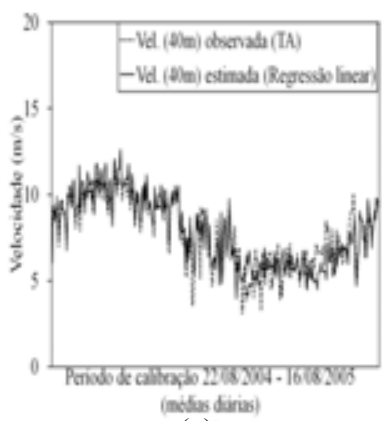

(a)

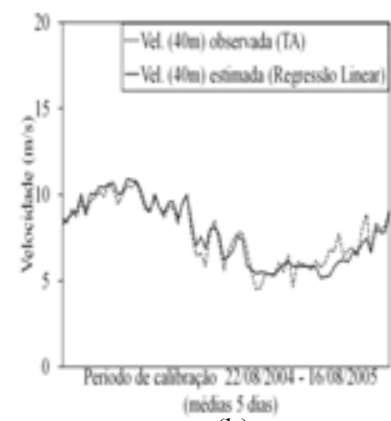

(b)

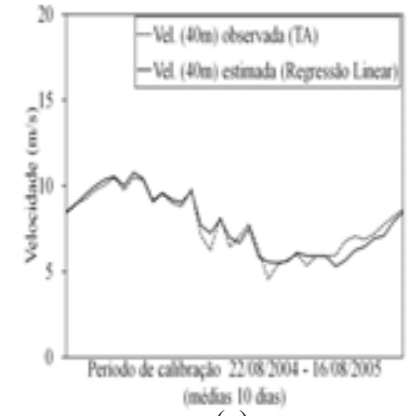

(c)

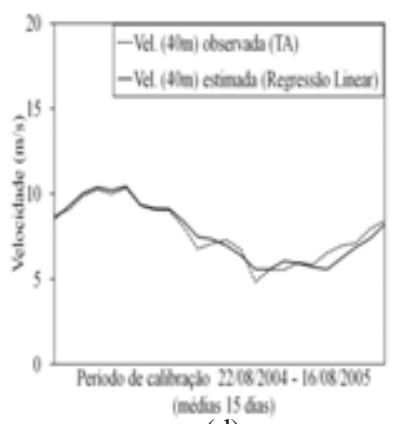

(d)

Figura 30 - Comparação entre as séries de dados estimados pela regressão linear e os dados observados na TA de Camocim para a altura de 40 metros no período de calibração, para médias diárias (a), para médias de 5 (b), de 10 (c) e de 15 dias (d)

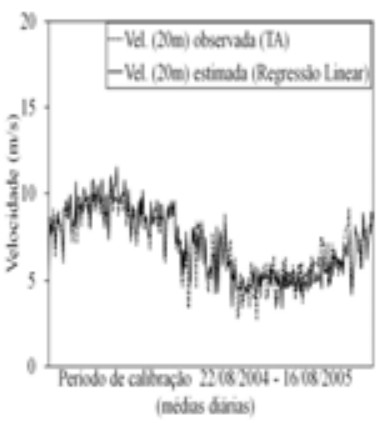

(a)

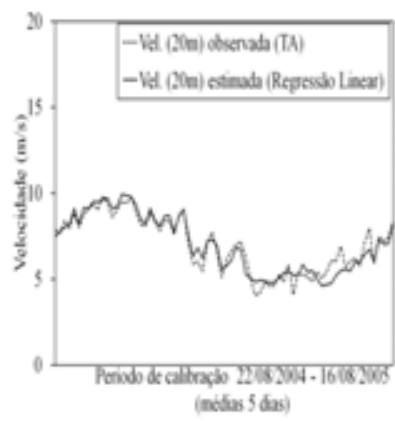

(b)

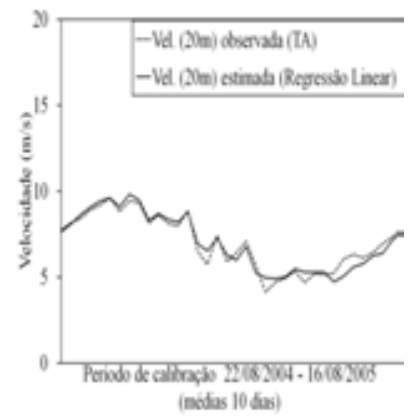

(c)

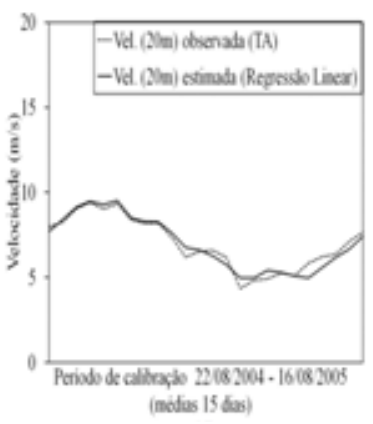

(d)

Figura 31 - Comparação entre as séries de dados estimados pela regressão linear e os dados observados na TA de Camocim para a altura de 20 metros no período de calibração, para médias diárias (a), para médias de 5 (b), de 10 (c) e de 15 dias (d). 
Tabela 3 - Valores dos erros e coeficientes de correlação e determinação entre os dados estimados na TA pelas equações das retas de regressão e os dados observados na TA no período de calibração em Camocim.

\begin{tabular}{|c|c|c|c|c|c|c|}
\hline $\begin{array}{c}\text { Altura } \\
(\mathbf{m})\end{array}$ & $\begin{array}{l}\text { Períodos nos quais se obteve as } \\
\text { Médias das velocidades do vento }\end{array}$ & $\begin{array}{c}\text { RMSE } \\
(\mathbf{m} / \mathbf{s})\end{array}$ & $\begin{array}{r}\text { MAE } \\
(\mathbf{m} / \mathbf{s})\end{array}$ & $\begin{array}{c}\varepsilon \\
(\%)\end{array}$ & $\mathbf{r}$ & $\mathbf{R}^{2}$ \\
\hline \multirow{4}{*}{$\underset{\text { తి }}{\Xi}$} & Diárias & 0,80 & 0,61 & 0,56 & 0,91 & 0,83 \\
\hline & 5 dias & 0,50 & 0,39 & 0,24 & 0,95 & 0,90 \\
\hline & 10 dias & 0,39 & 0,31 & 0,19 & 0,97 & 0,94 \\
\hline & 15 dias & 0,36 & 0,28 & 0,06 & 0,97 & 0,94 \\
\hline \multirow{4}{*}{$\stackrel{\Xi}{\stackrel{\Xi}{f}}$} & Diárias & 0,92 & 0,69 & 1,16 & 0,89 & 0,79 \\
\hline & 5 dias & 0,55 & 0,41 & 0,04 & 0,95 & 0,90 \\
\hline & 10 dias & 0,44 & 0,33 & 0,04 & 0,97 & 0,94 \\
\hline & 15 dias & 0,40 & 0,30 & 0,02 & 0,97 & 0,94 \\
\hline \multirow{4}{*}{$\stackrel{\Xi}{\Xi}$} & Diárias & 0,94 & 0,71 & 0,87 & 0,90 & 0,81 \\
\hline & 5 dias & 0,57 & 0,44 & 0,03 & 0,95 & 0,90 \\
\hline & 10 dias & 0,47 & 0,36 & 0,16 & 0,97 & 0,94 \\
\hline & 15 dias & 0,42 & 0,33 & 0,05 & 0,97 & 0,94 \\
\hline
\end{tabular}

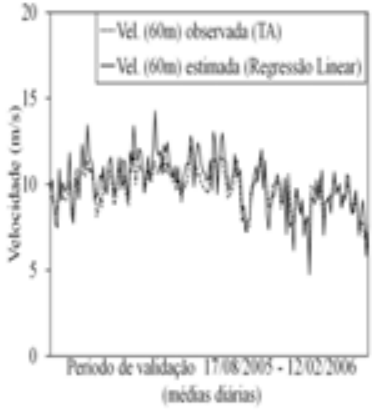

(a)

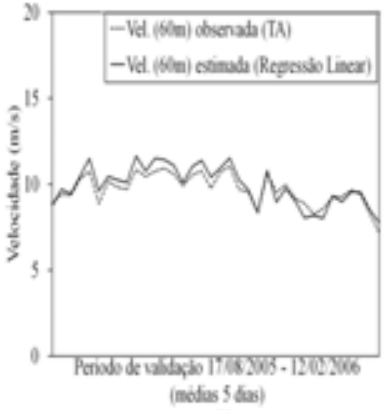

(b)

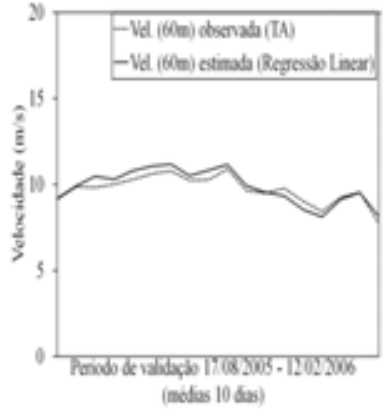

(c)

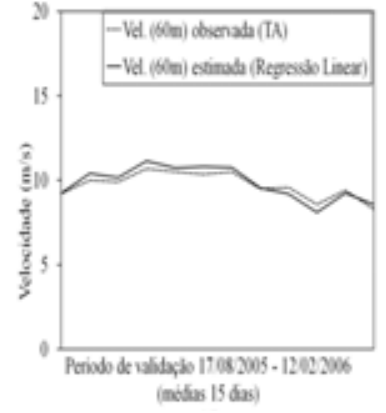

(d)

Figura 32 - Comparação entre as séries de dados estimados pela regressão linear e os dados observados na TA de Camocim para a altura de 60 metros no período de validação, para médias diárias (a), para médias de 5 (b), de 10 (c) e de 15 dias (d).

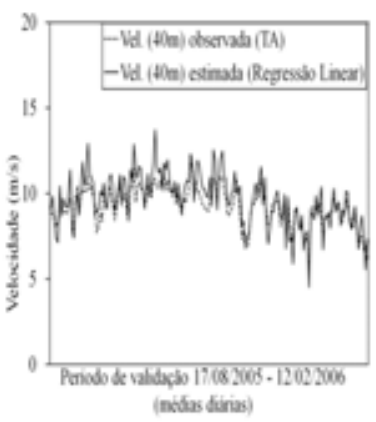

(a)

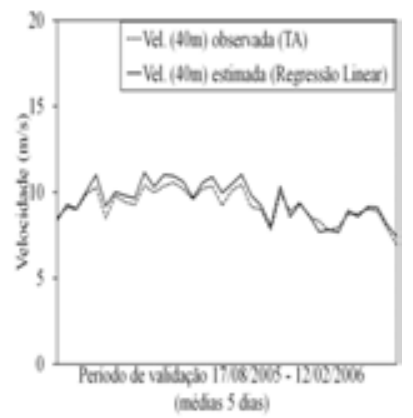

(b)

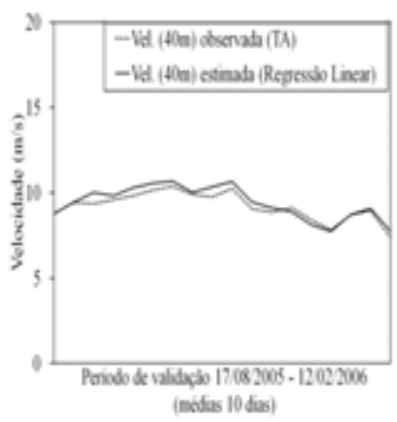

(c)

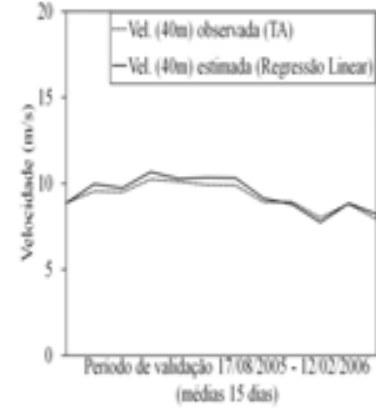

(d)

Figura 33 - Comparação entre as séries de dados estimados pela regressão linear e os dados observados na TA de Camocim para a altura de 40 metros no período de validação, para médias diárias (a), para médias de 5 (b), de 10 (c) e de 15 dias (d).

os mesmos erros que foram calculados para a região de Paracuru, bem como os coeficientes de correlação e determinação entre os dois conjuntos de dados. Os resultados são mostrados na Tabela 4.

Observa-se que a 20 metros de altura, ocorreram os menores valores de RMSE, MAE e $\varepsilon$ que foram, respectivamente, $0,24 \mathrm{~m} / \mathrm{s}, 0,21 \mathrm{~m} / \mathrm{s}$ e $1,0 \%$, todos encontrados para a comparação entre as séries de valores médios estimados e observados de
15 dias, em que também se verifica o coeficiente máximo de correlação $(0,98)$ e o coeficiente máximo de determinação que explica $96 \%$ da variabilidade dos dados observados.

Em 40 metros, tem-se que os menores valores de RMSE, MAE e $\varepsilon$ foram respectivamente, $0,28 \mathrm{~m} / \mathrm{s}, 0,25 \mathrm{~m} / \mathrm{s}$ e $1,8 \%$, para a comparação entre as séries de valores médios estimados e observados de 15 dias, onde se tem o coeficiente máximo 
Tabela 4 - Valores dos erros e coeficientes de correlação e determinação entre os dados estimados na TA pelas equações das retas de regressão e os dados observados na TA no período de validação para a região de Camocim.

\begin{tabular}{|c|c|c|c|c|c|c|}
\hline $\begin{array}{c}\text { Altura } \\
(\mathbf{m})\end{array}$ & $\begin{array}{l}\text { Períodos nos quais se obteve as } \\
\text { médias das velocidades do vento }\end{array}$ & $\begin{array}{c}\text { RMSE } \\
(\mathbf{m} / \mathbf{s})\end{array}$ & $\begin{array}{l}\text { MAE } \\
(\mathbf{m} / \mathbf{s})\end{array}$ & $\begin{array}{c}\varepsilon \\
(\%) \\
\end{array}$ & $\mathbf{r}$ & $\mathbf{R}^{2}$ \\
\hline \multirow{4}{*}{$\underset{\text { ㄱ }}{\Xi}$} & Diárias & 0,72 & 0,58 & 3,7 & 0,90 & 0,81 \\
\hline & 5 dias & 0,34 & 0,28 & 1,9 & 0,97 & 0,94 \\
\hline & 10 dias & 0,28 & 0,24 & 1,5 & 0,97 & 0,94 \\
\hline & 15 dias & 0,24 & 0,21 & 1,0 & 0,98 & 0,96 \\
\hline \multirow{4}{*}{$\stackrel{\Xi}{\stackrel{\Xi}{\&}}$} & Diárias & 0,82 & 0,66 & 4,6 & 0,90 & 0,81 \\
\hline & 5 dias & 0,41 & 0,35 & 2,7 & 0,96 & 0,92 \\
\hline & 10 dias & 0,33 & 0,28 & 2,2 & 0,97 & 0,94 \\
\hline & 15 dias & 0,28 & 0,25 & 1,8 & 0,98 & 0,96 \\
\hline \multirow{4}{*}{$\begin{array}{l}\Xi \\
8\end{array}$} & Diárias & 0,84 & 0,68 & 3,7 & 0,89 & 0,79 \\
\hline & 5 dias & 0,44 & 0,37 & 2,1 & 0,95 & 0,90 \\
\hline & 10 dias & 0,37 & 0,32 & 1,7 & 0,95 & 0,90 \\
\hline & 15 dias & 0,32 & 0,29 & 1,2 & 0,97 & 0,94 \\
\hline
\end{tabular}

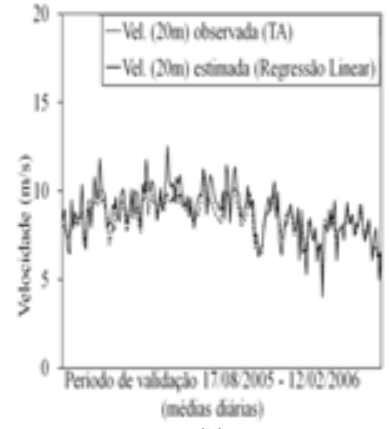

(a)

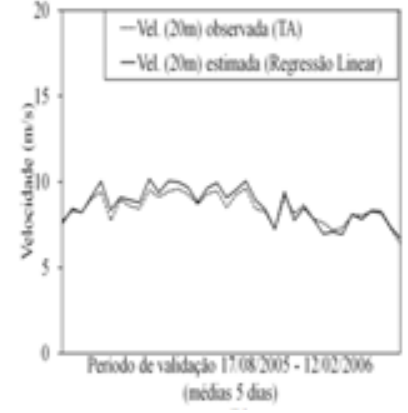

(b)

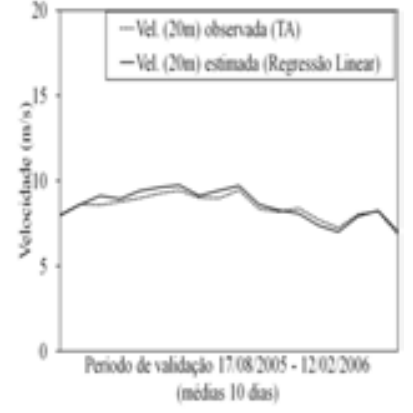

(c)

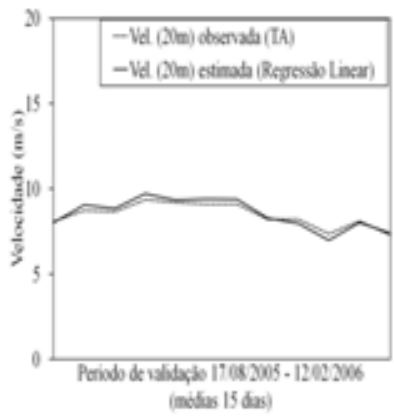

(d)

Figura 34 - Comparação entre as séries de dados estimados pela regressão linear e os dados observados na TA de Camocim para a altura de 20 metros no período de validação, para médias diárias (a), para médias de 5 (b), de 10 (c) e de 15 dias (d).

de correlação $(0,98)$ e o coeficiente máximo de determinação explica $(0,96)$, donde ambos explicam $96 \%$ da variabilidade dos dados observados.

Para 60 metros, os menores valores dos erros foram encontrados respectivamente, $0,32 \mathrm{~m} / \mathrm{s}, 0,29 \mathrm{~m} / \mathrm{s}$ e $1,2 \%$, para a comparação entre as séries de valores médios estimados e observados de 15 dias, em que se registra o coeficiente máximo de correlação $(0,97)$ e o coeficiente máximo de determinação explica $94 \%$ da variabilidade dos dados observados.

Novamente, tanto para o período de calibração, quanto para o de validação, os valores de RMSE e MAE são inferiores aos encontrados por Santiago de Maria et al (2006), quando o mesmo comparou os valores de velocidade média do vento observados na TA de Camocim com os valores simulados com o RAMS a 20, 40 e 60 metros. Entretanto, os valores dos coeficientes de correlação aqui apresentados, em geral, coincidem com os valores encontrados pelo autor acima citado. Vale mencionar que os coeficientes de correlação e seus resultados via reta de regressão ajustada, tanto nos períodos de calibração, como nos de validação para períodos médios de 10 e 15 dias, devem ser interpretados com cautela, pois devido aos dados das PCDs terem muitas falhas no período de estudo e terem sido instaladas recentemente, a amostra para este período de dias é pequeno para o ajuste da reta de regressão ser estatisticamente confiável.

\section{CONSIDERAÇÕES FINAIS}

O modelo de regressão linear no qual esse estudo se baseou, mostrou satisfatório desempenho, tanto no período de calibração, quanto no período de validação do modelo, seja pelo alto índice de concordância entre as séries de dados estimados e a série de dados observados e seus respectivos coeficientes de correlação, seja pelos baixos valores dos erros quantificados.

Embora o modelo tenha sido utilizado para regiões litorâneas do Estado do Ceará, existe a possibilidade do mesmo ser utilizando-se dados das PCDs localizadas em regiões do interior do Estado.

Diante dos resultados obtidos, confirma-se que as regiões de Paracuru e Camocim caracterizam-se como potenciais sítios, favoráveis para o aproveitamento da energia eólica. Conclui-se ainda, que a estimativa de recursos eólicos em altitude a partir 
de dados observados em superfície, usando-se a metodologia proposta nesse trabalho, é um processo viável tanto do ponto de vista técnico quanto financeiro.

Para trabalhos futuros nessa linha de investigação, estimativa de recursos eólicos, propõe-se o uso de regressão linear múltipla, ou seja, a utilização de uma única variável dependente, porém com duas ou mais variáveis independentes, com a finalidade de se melhorar a capacidade de estimativa.

Outra possibilidade é a quantificação do potencial energético a partir dos valores de velocidade média do vento observados nas TAs e os valores estimados pelo modelo de regressão linear a partir dos dados de superfície.

\section{REFERÊNCIAS BIBLIOGRÁFICAS}

ALCÂNTARA, C. R.; SOUZA, E. P. Uma teoria termodinâmica para brisas: testes utilizando simulações numéricas. Revista Brasileira de Meteorologia, v.23, n.1, p.1-11, março, 2008.

ANDREOLI, R. V., KAYANO, M. T., GUEDES, R. L., OYAMA. M. D., ALVES, M. A. S. A influência da temperatura da superfície do mar dos oceanos Pacífico e Atlântico na variabilidade da precipitação em Fortaleza. Revista Brasileira de Meteorologia, v.19, n.2, p.113-122, setembro, 2004.

BARRETO, A. B., ARAGÃO, M. R. S.; BRAGA, C. C. Estudo do ciclo diário do vento à superfície no Nordeste do Brasil. In: CONGRESSO BRASILEIRO DE METEOROLOGIA, 12, 2002, Foz de Iguaçu. Anais... XII Congresso Brasileiro de Meteorologia, 2002.

CARVALHEIRO, L. C. O. et al. Validação da Temperatura da Superfície do Mar a partir de medições de satélite. Disponível em <www.ame-web.org/JORNADAS/6B_ Carvalheiro.pdf>. Acesso em: 15 setembro 2009.

CARVALHO, P. Geração eólica. Fortaleza: Imprensa Universitária, 2003. 146 p.

CASTRO, R. M. G. Energias Renováveis e Produção Descentralizada: introdução à energia eólica. 3 ed. Lisboa, Universidade Técnica de Lisboa, 2007.

DOBRIANSKY, P. Energia limpa para o futuro. Revista e Journal USA: Perspectivas Econômicas, Washington, D.C, v 11, n. 2, 4-6, 2006.

HIRATA, M. H., MOURA, A. D., BACHMANN, J. A study of the influence of extra-tropical latitudes systems on the climatic variability on northeast Brazil. Revista Brasileira de Meteorologia, v.1, n.1, p.11-17, junho, 1986.
KOUSKY, V. E. Frontal influence in Northeast Brazil. Monthly Weather Review, v.107, p.1140-1153, 1979.

KOLMOGOROV-SMIRNOV. Disponível em < www.physics. csbsju.edu/stats/KS-test.html >. Acesso em: 15 outubro 2009.

MOLION, L. C. B., BERNARDO, S. de O. Variabilidade do vento para cidade de Maceió-AL. In: CONGRESSO BRASILEIRO DE METEOROLOGIA, 11, 2000, Rio de Janeiro. Anais...XI Congresso Brasileiro de Meteorologia, 2000.

OLIVEIRA, J. L.. Influência da circulação geral e da variabilidade interanual sobre o potencial eólico do Nordeste brasileiro. 2007. Dissertação (Mestrado em Ciências Físicas Aplicadas) - Universidade Estadual do Ceará, 2007.

RAO, V. B., LIMA, M. C., FRANCHITO, S. Seasonal and interannual of rainfall in Northeast Brazil. Journal of Climate, Boston, v.6, p.1754-1763, 1993.

ROBALLO, S. T., FISCH, G. Escoamento atmosférico no Centro de Lançamento de Alcântara (CLA): Parte I: Aspectos observacionais. Revista Brasileira de Meteorologia, v.23, n.4, p.510-519, dezembro, 2008.

SACRAMENTO, E. M. et al. Estudo preliminar sobre o potencial eólico das regiões serranas do Ceará. In: CONGRESSO BRASILEIRO DE METEOROLOGIA, 14, 2006. Florianópolis. Anais... XIV Congresso Brasileiro de Meteorologia, 2006.

SANTIAGO DE MARIA, P. H. S., COSTA, Alexandre A, SOMBRA, Sérgio S. Simulação de ventos em alta resolução no litoral do Ceará. In: CONGRESSO BRASILEIRO DE METEOROLOGIA, 14, 2006, Florianópolis. Florianópolis. Anais... XIV Congresso Bras. de Meteorologia, 2006.

SEINFRA. Dados Anemométricos (Medição de Ventos) Paracuru e Camocim. Disponível em: $<$ http://www.seinfra. ce.gov.br/index.php/downloads/category/3-energia $>$. Acesso em: 25 maio 2009.

STULL, R.B. An introduction to Boundary Layer Meteorology. (Kluwer Academic Publishers, Dordrecht, 1988).

TEIXEIRA, R. F. B. O fenômeno da brisa e sua relação com a chuva sobre Fortaleza-CE. Revista Brasileira de Meteorologia, v.23, n.3, p.282-291, setembro, 2008. VIANELLO, R. L., ALVES, R. A. Meteorologia Básica e Aplicações. Viçosa, UFV. Impr. Univ. 1991.

XAVIER, T. M. S., XAVIER, A. F., DA SILVA DIAS, P. L., DA SILVA DIAS, M. A. F. AZona de Convergência Intertropical - ZCIT e as suas relações com chuva no Ceará (1964-98). Revista Brasileira de Meteorologia, v.15, n.1, p.27-43, junho, 2000. 